Research Article

\title{
The Physicomechanical Deterioration Characteristics and Mesoscopic Damage Analysis of Sandstone under Acidic Environment
}

\author{
Runke Huo, ${ }^{1,2}$ Tian Qiu, ${ }^{1,2}$ Yanling Liang $\mathbb{D}^{1,2}$ Shuguang Li $\mathbb{D},{ }^{1,2,3,4}$ and Meiting Qian ${ }^{1,2}$ \\ ${ }^{1}$ School of Civil Engineering, Xi'an University of Architecture and Technology, Xi'an 710055, China \\ ${ }^{2}$ Shanxi Key Lab of Geotechnical and Underground Space Engineering, Xi'an 710055, China \\ ${ }^{3}$ Postdoctoral Research Workstation, China Railway 20th Bureau Group Co., Ltd., Xi'an 710016, China \\ ${ }^{4}$ ReD Center of Plateau Tunnel Construction Technology and Equipment, China Railway 20th Bureau Group Co., Ltd., \\ Xi'an 710016, China \\ Correspondence should be addressed to Yanling Liang; 118220585037@163.com and Shuguang Li; 1ssgg2015@163.com
}

Received 10 February 2020; Revised 21 June 2020; Accepted 30 June 2020; Published 30 July 2020

Academic Editor: Timo Saksala

Copyright (C) 2020 Runke Huo et al. This is an open access article distributed under the Creative Commons Attribution License, which permits unrestricted use, distribution, and reproduction in any medium, provided the original work is properly cited.

\begin{abstract}
The physicomechanical deterioration characteristics of sandstone subjected to $\mathrm{H}_{2} \mathrm{SO}_{4}, \mathrm{HCl}$, and $\mathrm{H}_{2} \mathrm{O}$ solutions of different $\mathrm{pH}$ values are studied by the method of long-term accelerated immersion. The quantitative relationships between the damage variables based on CT (computer tomographic identification technology) numbers and the immersion time, the uniaxial compressive strength, the peak point strain, and the elastic modulus of rock samples are analyzed. The test results indicate that the $\mathrm{pH}$ value of immersion solutions, the dissolution rate of $\mathrm{Ca}^{2+}$ and $\mathrm{Na}^{+}$, and the quality change of rock samples show visible stage characteristics under acidic environment. With the soaking time extended, the $\mathrm{pH}$ value of solutions increases gradually, and the quality change of rock samples decreases gradually. The smaller the $\mathrm{pH}$ value of immersion solutions is, the higher the dissolution rate of $\mathrm{Ca}^{2+}$ and $\mathrm{Na}^{+}$is. However, the cation dissolution rate under a weak acid environment with a high $\mathrm{pH}$ value has little difference with that under the distilled water $(\mathrm{pH}=7)$. With the increase of the soaking time and the acidity, the compaction stage of rock samples becomes longer, the elastic stage becomes shorter, the deterioration degree of mechanical parameters becomes more extensive, and the destruction of sandstone samples shows ductility characteristics increasingly. The corrosion degree of corroded sandstone samples is quantitatively represented by microscopic damage variables based on CT numbers. The regression analysis results show that damage variables of acid-corroded sandstone samples have a power function relationship with soaking time and an exponential function relationship with peak strength, peak point strain, and elastic modulus.
\end{abstract}

\section{Introduction}

The worsening of environmental pollution has caused rock and concrete materials to suffer corrosion destruction of varying degrees during their service [1-3]. The action of chemical media in the natural environment causes materials such as rocks to have a performance degradation and even are corroded. Although this process is slow, the cumulative effect of long-term corrosion cannot be ignored.

In recent years, the research on the influence of acid corrosion on the physical and mechanical properties of rocks has been valued by relevant scholars at home and abroad. It has become one of the emerging research focuses in the field of rock and environmental geotechnical engineering. Mohtarami et al. $[4,5]$ studied the effect of chemical solutions on the physical and mechanical properties of rocks and analyzed the chemical effect of rock fracture by the finite element method. Portier and Vuataz [6] studied the response of Enhanced Geothermal System (EGS) reservoir to chemical stimulation by numerical simulation of coupled thermohydraulic-chemical processes. Taron and Elsworth [7] introduced a new methodology and numerical simulator for the modelling of thermal-hydraulic mechanical-chemical processes in dual-porosity media. Chen et al. [8] had carried out 
microscopic mechanical tests on the uniaxial compression fracture process of rocks under chemical corrosion, discussed the corrosion effect of different chemical solutions on uniaxial compression strength of rocks, and analyzed the microfracture characteristics and corrosion mechanism of rock under chemical etching. Huo et al. [9-12] and Li et al. [13, 14] obtained the evolution laws of physical, chemical, and mechanical properties of acid corrosion sandstone and mortar by the indoor long-term accelerated corrosion test under acidic environment, established the constitutive model of sandstone in acid solutions, deduced the damage variables of acid corrosion sandstone based on CT numbers, and revealed the corrosion mechanism of sandstone under acidic environment. Xu et al. [15] and Li et al. [16] had carried out shear strength tests of sandstone subjected to different water chemical solution erosion. The mechanism of chemical damage of sandstone was discussed, and the relationship between porosity and shear strength was established. The influence of hydrochemical corrosion on the sandstone destruction, crack opening, and expansion direction was obtained. Chen et al. [17], Ding et al. [18], Han et al. [19], and Gao et al. [20] had performed the physical and mechanical tests on the chemical corrosion and freeze-thaw cycles of granite, limestone, sandstone, and red sandstone, respectively. The physical and mechanical damage laws of rock under the combined action of the freeze-thaw cycle and water chemical solution were analyzed. Wang et al. [21, 22] and Han et al. [23] had studied the effect of chemical solution soaking on the mechanical properties of sandstone and sand slate by uniaxial and triaxial compression tests. They found that the mechanical properties of sandstone decrease obviously after chemical corrosion, and it is closely related to the change of porosity. The conclusion that the elastic modulus and compressive strength of rocks decrease with the increase of soaking time and acidity was drawn. He and Guo [24] studied the failure of rock strength affected by different acid solutions from macroscopic and microscopic perspectives through core tests. Ding et al. [25] studied the mechanical damage characteristics and chemical dissolution behaviour of limestone under different chemical solutions. A time-dependent damage equation of the uniaxial compressive strength of limestone was developed under various chemical solutions. Chemical dynamic erosion equations of limestone were developed. Xie et al. [26] had carried out conventional triaxial and rheological tests on natural limestone and chemically etched porous limestone, respectively. They analyzed the effects of chemical corrosion on the pore-changing and aged mechanical properties of limestone. In recent years, the study of microscopic damage to rock by CT nondestructive testing technology is emerging $[27,28]$. Yang et al. [29] applied the CT detection techniques for the study of rock damage characteristics, established the mathematical model of CT number distribution in damaged rocks, and deduced the formula for expressing rock damage variables by CT numbers. $\mathrm{Fu}$ et al. [30] analyzed the evolution mechanism of the microscopic damage of rock samples under the action of dry-wet cycles through CT scanning tests of sandstone with different initial microstructures. They obtained the damage evolution equation of sandstone.
The current research results mainly focus on the influence of chemical solutions on the macroscopic mechanical properties of rocks, lacking quantitative analysis of the effect of long-term accelerated corrosion and acidic solutions of different chemical compositions on the physical and mechanical properties of rocks. In this paper, the common sandstone in water conservancy and civil engineering is taken as the research object. The physical and mechanical properties of sandstone under acidic environment are systematically studied based on the uniaxial compression test. The quantitative relationship between damage variables and soaking time and mechanical parameters is established, which provides a basis for quantifying the deterioration degree of rocks in the acid environment.

\section{Materials and Methods}

2.1. Preparation of Sandstone Samples and Chemical Solutions. The sandstone specimen used in the tests were sampled from the water conservancy project in Shanxi Province, China, where the sandstone samples have good integrity and homogeneity. The rock samples were taken from the same rock mass to ensure uniformity. The X-ray diffraction test identified that the name of the sandstone is green-grey finegrained calcareous feldspar sandstone with fine-grained unequal-grained structure. The particle size of debris is $0.05 \mathrm{~mm}$ to $0.45 \mathrm{~mm}$, and the shape of debris is irregular, mainly angular-subangular, and a little subcircular. The detrital components are mainly quartz, feldspar, mica, chlorite, siliceous, and limestone clastic. The sandstone sample composition is shown in Table 1, and the microstructure diagram is shown in Figure 1.

According to the provisions of international rock mechanics, the sample was processed into a cylinder with a diameter of $50 \mathrm{~mm}$ and a height of $100 \mathrm{~mm}$. The basic dimensions and machining accuracy were in line with the Standard for Tests Method of Engineering Rock Masses [31]. Before the test, the samples were sonic tested, and the samples with a significant difference in wave velocity were excluded. The sandstone samples were grouped according to the longitudinal wave velocity. Considering the complexity of the acidic environment in nature, two acids (sulfuric acid and hydrochloric acid) were chosen to simulate the acidic environment. And, taking into account the strong acid, the medium-strong acid, and the weak acid, the $\mathrm{pH}$ values were set to 1,3 , and 5 . Therefore, hydrochloric acid and sulfuric acid solutions $(\mathrm{pH}=1,3$, and 5) and distilled water solution $(\mathrm{pH}=7)$ were prepared, as shown in Figure 2. A total of 60 samples were selected and divided into four groups. There are 8 rock samples in each solution with $\mathrm{pH}=1,3,5$, or 7 . Grouping and soaking of sandstone samples are shown in Table 2. Sandstone samples were soaking in the above solutions for the corrosion test.

2.2. Test Apparatus. The $\mathrm{pH}$ test equipment and ion concentration test equipment used in the experiment are Leica PHS-3C and Metrohm 792 Basic IC, respectively. The 
TABLE 1: Debris components and contents.

\begin{tabular}{lc}
\hline Cuttings composition & Content (\%) \\
\hline Quartz & 58 \\
Feldspar & 11 \\
Calcite & 5 \\
Mica & 3 \\
Chlorite & 1 \\
Siliceous cuttings & 6 \\
Limestone cuttings & 2 \\
Cement & 7 \\
Clay & 3 \\
Heavy minerals & Occasionally \\
\hline
\end{tabular}

weighing instrument is an electronic balance JA12002 with a division value of $0.01 \mathrm{~g}$. The oven is WGL-30B with a temperature range of room temperature plus $5 \sim 300^{\circ} \mathrm{C}$. The uniaxial compression tests were conducted in the LETRY electrohydraulic rock pressure testing machine (Figure 3). The maximum axial load was $2000 \mathrm{KN}$. Philips Brilliance 16 spiral CT machine (Figure 4) was used to obtain the CT images of the samples. The spatial resolution was $0.208 \mathrm{~mm} \times 0.208 \mathrm{~mm}$. The density contrast resolution was $0.3 \%(\mathrm{Hu})$. The image storage matrix was $1024 \times 1024$. The CT number range was minus 1024 plus 3071 .

2.3. Test Methods. In this paper, hydrochloric acid solutions, sulfuric acid solutions with $\mathrm{pH}=1,3$, and 5 , and distilled water solution with $\mathrm{pH}=7$ were used to simulate the hydrochemical environment. The sandstone specimens were soaked and corroded at room temperature and atmospheric pressure. The experiment was divided into six stages (S1-S6), every 30 days for a stage. In order to observe obvious changes of corrosive sandstone samples in a relatively short time, the soaking solution was renewed every 30 days during the test (the type and $\mathrm{pH}$ of the replacement solution were unchanged). Before the experiment, the numbered sandstone samples were photographed, and the initial mass was weighted (Table 2). Then, the rock samples were placed in the prepared solutions, and the soaking container was a ground glass beaker. During the soaking process, the beaker was sealed to prevent carbon dioxide from entering, and the $\mathrm{pH}$ value and ion concentration of solutions and the mass of samples were measured. When the soaking time reached 30,60, 90, and 180 days, the samples were taken out for the uniaxial compression test, and the CT scanning test was carried out on sandstone samples at 0,30 , 90 , and 180 days.

\section{Results and Discussion}

3.1. Relative Change Law of Masses of Sandstone Samples. During soaking, the samples were taken out from the solution every 10 days. First, the surface water of the samples was wiped off with a cotton cloth, so that there was no dripping liquid. Then, the samples were left in the air for 5 minutes to ensure that the liquid is volatilized and dried. They were weighed in an electronic scale, and the values were recorded; after that, they were kept in an oven for drying

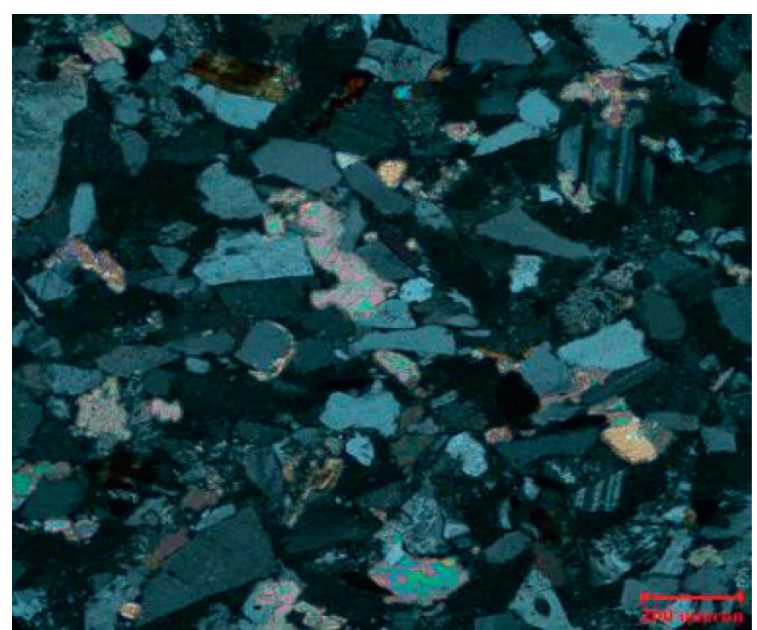

Figure 1: Microscopic image of the sandstone sample.

$\left(24 \mathrm{~h}, 105^{\circ} \mathrm{C}\right)$, and then they were taken out and weighed. The average values of the weight of samples were taken as the test result. The mass loss rate $L$ is defined as the ratio of the mass loss of the sandstone samples after acid corrosion to its initial mass. The formula is as follows:

$$
L=\frac{M_{0}-M_{t}}{M_{0}} \times 100 \%,
$$

where $M_{0}$ and $M_{t}$ are the weight of the samples in natural state and weight of the dry samples after soaking for $t$ days (g), respectively.

The relative mass change rate curves can reflect the extent of interaction of acid and sandstone indirectly. As can be seen from Figure 5, we have the following.

With the increase of soaking time, the change laws of the mass loss rate of sandstone samples soaked in different $\mathrm{pH}$ solutions are the same basically. The growth rate is faster in the early stage of immersion and gradually tends to be stable later. In the early stage of acid rock reaction, the erosion of the solution is mainly concentrated on the rock surface, and the chemical reaction rate is fast. With the extension of the penetration corrosion path, the acid rock reaction rate tends to be stable gradually. The smaller the $\mathrm{pH}$ value of the soaking solution is, the more violent the reaction between the soaking solution and the rock is, the higher the change rate and amplitude of the mass loss rate are, and the more bubbles and flocs are produced during the soaking process. When the soaking time reaches 180 days, the mass loss rates of the samples in $\mathrm{HCl}$ and $\mathrm{H}_{2} \mathrm{SO}_{4}$ solutions with $\mathrm{pH}=1,3$, and 5 are $1.28 \%$ and $1.09 \%, 0.84 \%$ and $0.72 \%$, and $0.61 \%$ and $0.59 \%$, respectively. The mass loss rate of samples in distilled water with $\mathrm{pH}=7$ is $0.58 \%$.

There are significant differences in the mass loss rate of sandstone samples in different types of soaking solutions with different $\mathrm{pH}$ values. Under the same conditions, the change amplitude and change rate of the mass loss rate in $\mathrm{HCl}$ solution are higher than those in $\mathrm{H}_{2} \mathrm{SO}_{4}$ solution during the initial soaking stage, and the change rate is basically the same in the later period of soaking. The mass loss rate of sandstone samples in $\mathrm{HCl}$ solution is slightly higher than 

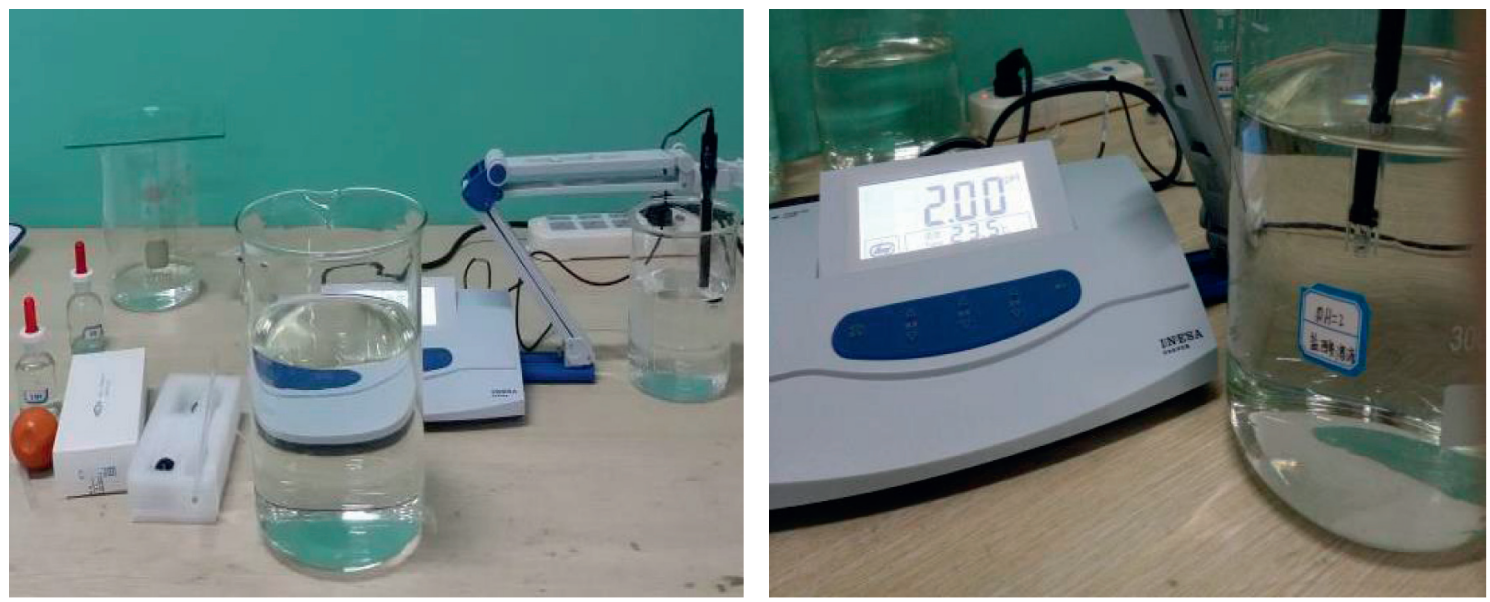

FIgURe 2: Preparation of acidic solutions.

TABLE 2: Sandstone samples grouping.

\begin{tabular}{|c|c|c|c|c|c|}
\hline Group number & $\mathrm{pH}$ value & Soaking state & Sample number & Wave velocity range $(\mathrm{m} / \mathrm{s})$ & Mass range \\
\hline 1 & & Natural rock samples & $\# 1 \sim 4$ & $2467 \sim 2775$ & $529.67 \sim 534.8$ \\
\hline 2 & $1,3,5$ & Sulfuric acid & $\# 5 \sim 28$ & $2416 \sim 2477$ & $523.93 \sim 533.08$ \\
\hline 3 & $1,3,5$ & Hydrochloric acid & $\# 29 \sim 52$ & $2941 \sim 2973$ & $522.69 \sim 528.92$ \\
\hline 4 & 7 & Distilled water & $\# 53 \sim 60$ & $2487 \sim 2546$ & $522.41 \sim 529.26$ \\
\hline
\end{tabular}

that in $\mathrm{H}_{2} \mathrm{SO}_{4}$ solution after soaking, indicating that the $\mathrm{HCl}$ solution is more corrosive to sandstone than the $\mathrm{H}_{2} \mathrm{SO}_{4}$ solution. This is because the $\mathrm{H}_{2} \mathrm{SO}_{4}$ solution produces more water film and cement than the $\mathrm{HCl}$ solution during the acid rock reaction. The microsolutes such as calcium sulfate are adsorbed inside the sandstone samples, which causes the insoluble matter to block parts of pores and hinders the progress of the chemical reaction.

\subsection{The Change Law of $p H$ Value of the Soaking Solution.} Figure 6 shows the curves of the $\mathrm{pH}$ value change of sandstone samples soaked in different $\mathrm{pH}$ solutions for different days. As can be drawn from Figure 6, we have the following:

(1) The $\mathrm{pH}$ values of acidic solutions with $\mathrm{pH}=l, 3$, and 5 (Figures 6(a) and 6(b)) increase rapidly at the initial stage of each soaking period ( $0 \sim 5$ days). The $\mathrm{pH}$ values still increase after 5 days, but the growth rate slows down gradually. For example, the $\mathrm{pH}$ values of hydrochloric acid and sulfuric acid solutions are 2.12 and 2.02 on the 5 th day of the first soaking stage (0 30 days) and reach 3.24 and 3.12 after the first soaking stage. The acidic solution with $\mathrm{pH}=l$ changes from strong acid to medium-strong acid at the end of each soaking stage. The acidic solution with $\mathrm{pH}=3$ changes from medium-strong acid to weak acid at the end of each soaking stage. The acidic solution with $\mathrm{pH}=5$ shows weak alkalinity at the end of each soaking stage. Under the action of distilled water with $\mathrm{pH}=7$ (Figure 6(c)), the water rock reaction is slight. The $\mathrm{pH}$ value of the solution increases gradually at each soaking stage. After the end of each soaking stage, the $\mathrm{pH}$ value of the solution is between 7.28 and 7.86 , which shows slightly alkaline.

(2) Overall, the pH values of the hydrochloric acid solution increase slightly faster than those of the sulfuric acid solution with the same initial $\mathrm{pH}$ values under the same soaking period. The higher the $\mathrm{pH}$ value of solution after acid rock reaction is, the more the hydrogen ions are consumed during corrosion soaking, and the more violent the acid rock reaction is. The experimental data show that the hydrochloric acid solution is more corrosive on sandstone than sulfuric acid solution under the same conditions.

(3) The acid rock interaction is intense in the early stage. The smaller the $\mathrm{pH}$ value of the solution is, the larger the change of value is, indicating that the chemical corrosion is stronger. In a limited enclosed space, the acid rock reaction has a time effect that the reaction rate gradually decreases with the extension of soaking time. Sandstone samples have an acid corrosion reaction with $\mathrm{H}^{+}$in the acidic solution and the hydrolysis and ion exchange with distilled water. At the initial stage of soaking, the acid corrosion reaction is mainly on the surface of the sandstone. After a certain period of reaction, $\mathrm{H}^{+}$in the solution continuously penetrates the sandstone to cause the chemical action between water and rock. Therefore, the $\mathrm{pH}$ value of the solution changes greatly at the initial soaking stage, and $\mathrm{H}^{+}$is consumed gradually in the later stage of the reaction, which makes the $\mathrm{pH}$ value of the solution changeless. 


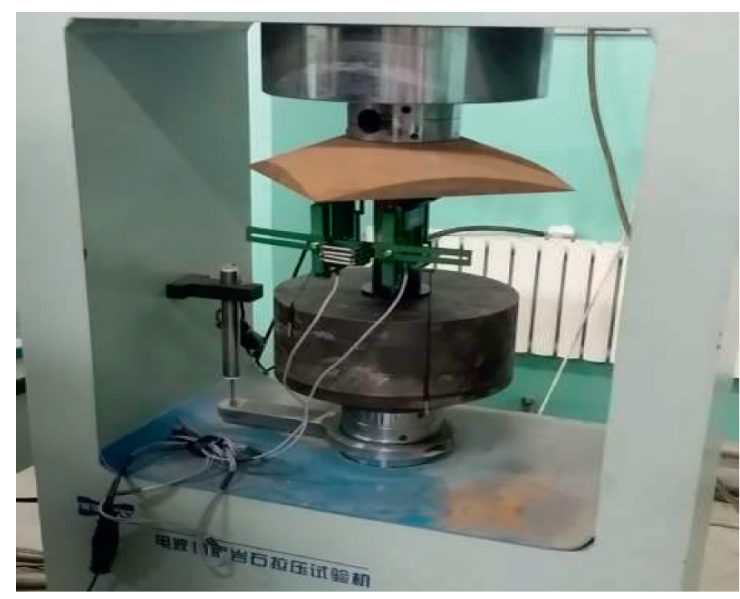

Figure 3: Uniaxial compression test.

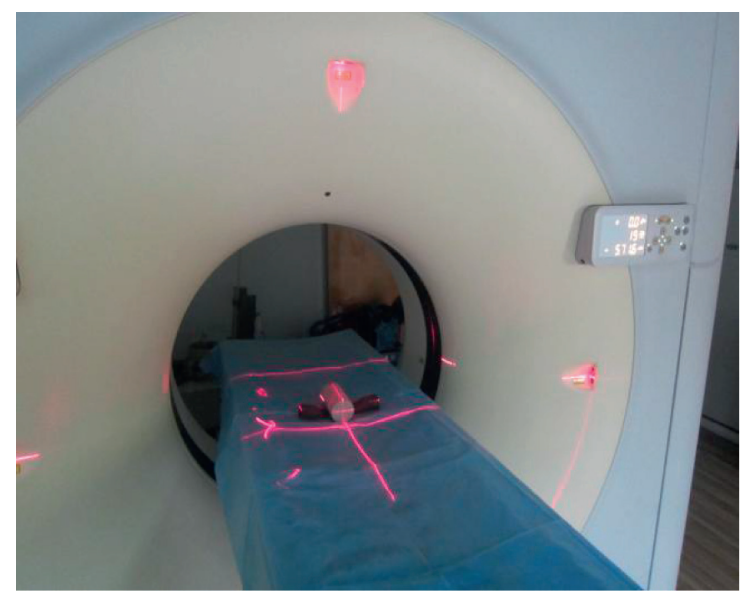

Figure 4: CT scanning test.

3.3. The Change Law of Cation Dissolution Rate. Define the cation dissolution rate in the solution as

$$
A=\frac{C_{t}-C_{0}}{\Delta t} \cdot V
$$

where $A$ is the dissolution rate of cation, $C_{0}$ is the initial concentration of cation $(\mathrm{mg} / \mathrm{L}), C_{t}$ is the concentration of cation after soaking $t$ days $(\mathrm{mg} / \mathrm{L}), \Delta t$ is the time difference before and after corrosion reaction $(d)$, and $V$ is the volume of the soaking solution $(L)$.

Figure 7 shows the variation curves of $\mathrm{Ca}^{2+}$ and $\mathrm{Na}^{+}$with soaking time in different $\mathrm{pH}$ solutions and different periods for sandstone samples. As can be drawn from Figure 7, we have the following.

The cation dissolution rate has a significant stage response over time. The smaller the $\mathrm{pH}$ value of the soaking solution is, that is, the stronger the acidity is, the more obvious the stage characteristic is. Under the same $\mathrm{pH}$ values of the soaking solution, the change law of the cation dissolution rate in each soaking stage (30 days) shows a downward trend as a whole. Under different $\mathrm{pH}$ values of the same soaking solution, during the initial to intermediate stage of soaking, the dissolution rate of $\mathrm{Ca}^{2+}$ and $\mathrm{Na}^{+}$

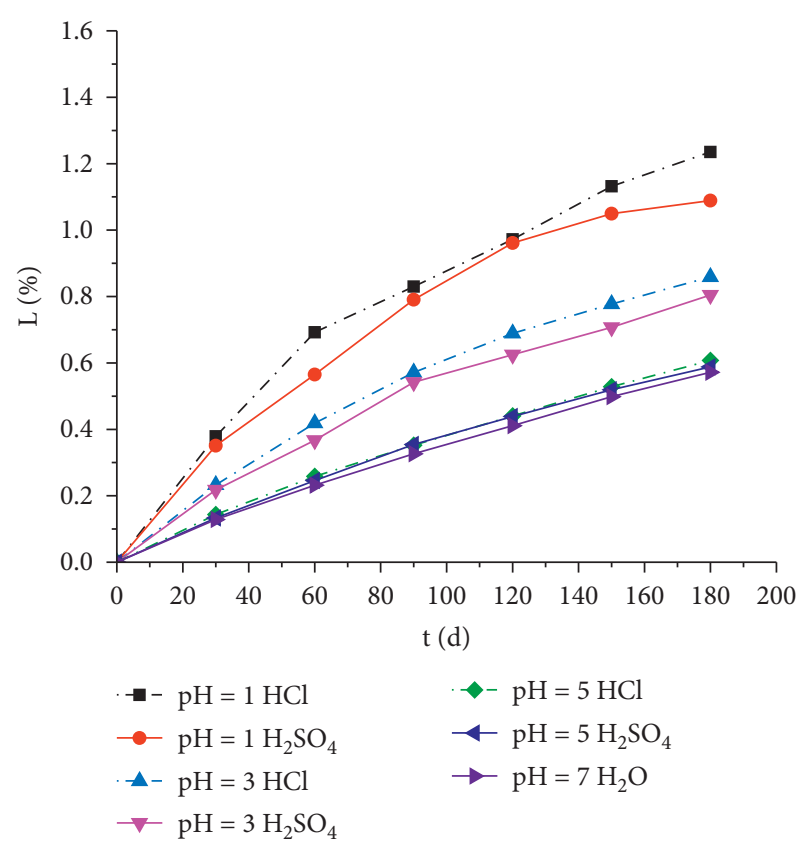

Figure 5: Mass loss rate curves of sandstone samples in different $\mathrm{pH}$ solutions.

decreases due to the increase of infiltration paths. During the middle to the late stage of soaking, the acid solution diffuses to the uncorroded area inside the rock sample, causing the dissolution rate to rise and then it continues to decrease.

Different soaking solutions have a great influence on the cation dissolution rate. Under the same conditions, the water film and cement produced by the reaction of $\mathrm{H}_{2} \mathrm{SO}_{4}$ and rock block the pores, resulting in the dissolution rate of $\mathrm{Ca}^{2+}$ under the action of the sulfuric acid solution which is lower than that under the action of hydrochloric acid solution. The dissolution rates of $\mathrm{Na}^{+}$in the two acidic solutions are approximately the same. When clay minerals such as montmorillonite and illite in sandstone are in an acidic environment, the action of dissolution, hydrolysis, and ion exchange affects the precipitation of ions contained therein. So, when the $\mathrm{pH}$ value is high, the dissolution degree of clay minerals is similar to that in distilled water solution. This is also the reason why the dissolution rate of the cation under the action of the acidic solution with $\mathrm{pH}=5$ (Figure 7) is not much different from that under the action of distilled water with $\mathrm{pH}=7$.

3.4. The Effect of Acidic Environment on Rock Mechanical Parameters. After soaking in the acid solution for 30, 60, 90, and 180 days, two sandstone samples were taken out for the uniaxial compression test. Because the effect of two samples under uniaxial pressure was similar, and the mechanical data were close, the experimental data of either of the two was selected as a result in the paper. The test results and stressstrain curves are shown in Table 3 and Figure 8, respectively.

(1) As can be seen from Figure 8, the stress-strain curve of sandstone can be divided into the following four stages: compaction phase, elastic phase, plastic 


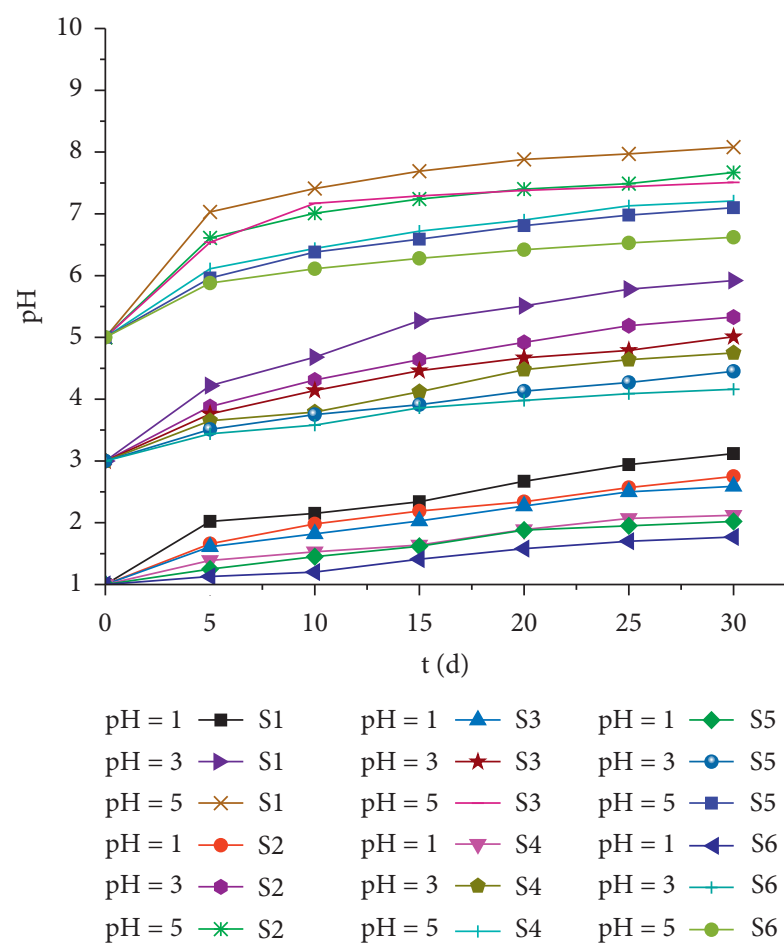

(a)

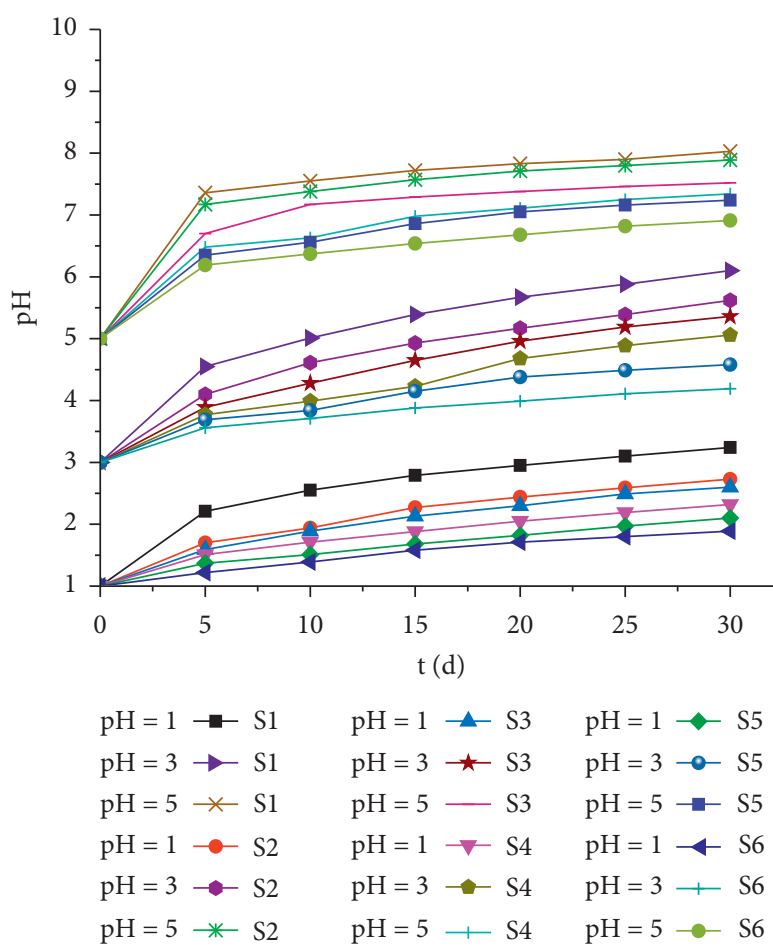

(b)

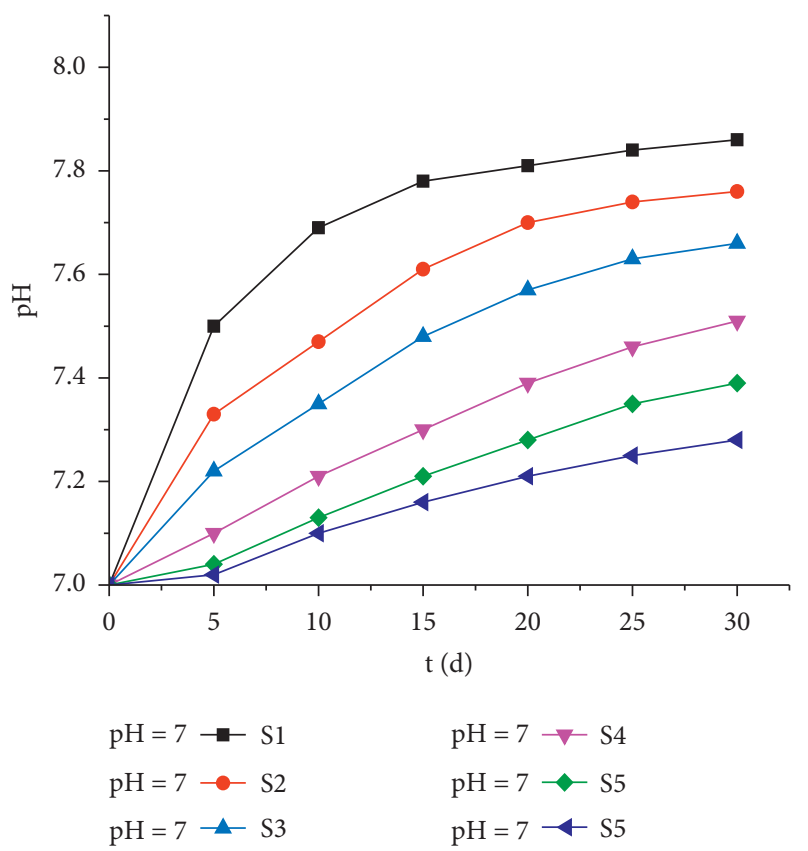

(c)

Figure 6: The change law of $\mathrm{pH}$ with time in different chemical solutions: (a) $\mathrm{H}_{2} \mathrm{SO}_{4}$ solution, (b) $\mathrm{HCl}$ solution, and (c) distilled water.

phase, and failure phase. The concave length of the natural specimen is short, and the degree of deformation is small. Then, it enters the elastic phase quickly. However, the compaction phase of the samples attacked by acid solution increases obviously. With the increases of axial pressure, the rock samples enter the elastic stage from the compaction stage. As can be seen from Table 3, the elastic modulus of acid-corroded sandstone samples all decreases to different extents compared with the sandstone in a natural state. The plastic deformation stage of the samples is not obvious. As can be seen from Table 3, the axial strain at the peak point of the sandstone samples increases gradually with the increase of the acidity of the chemical solution. Because of the strong brittleness of rock samples selected in 


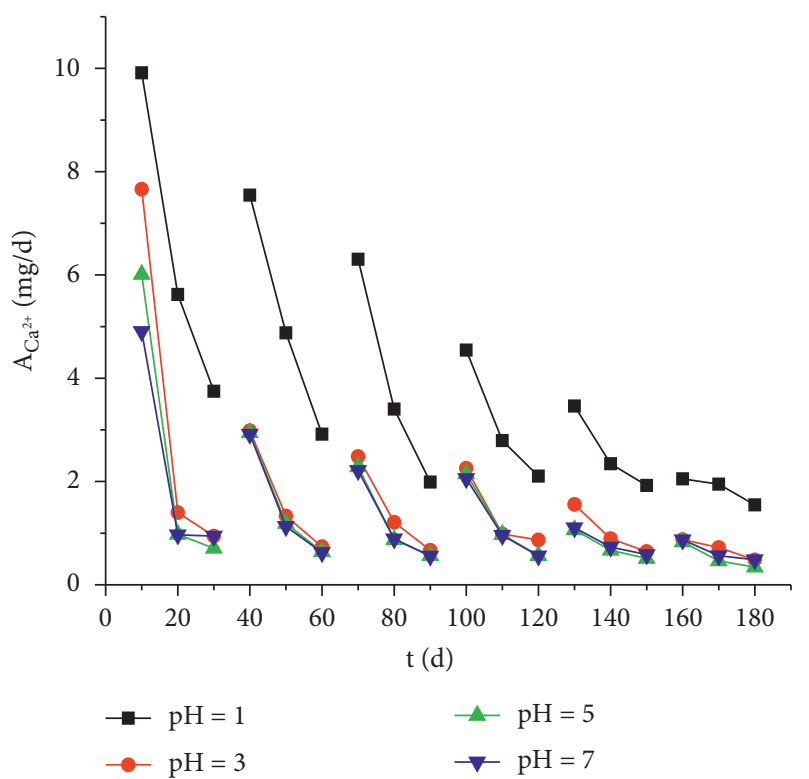

(a)

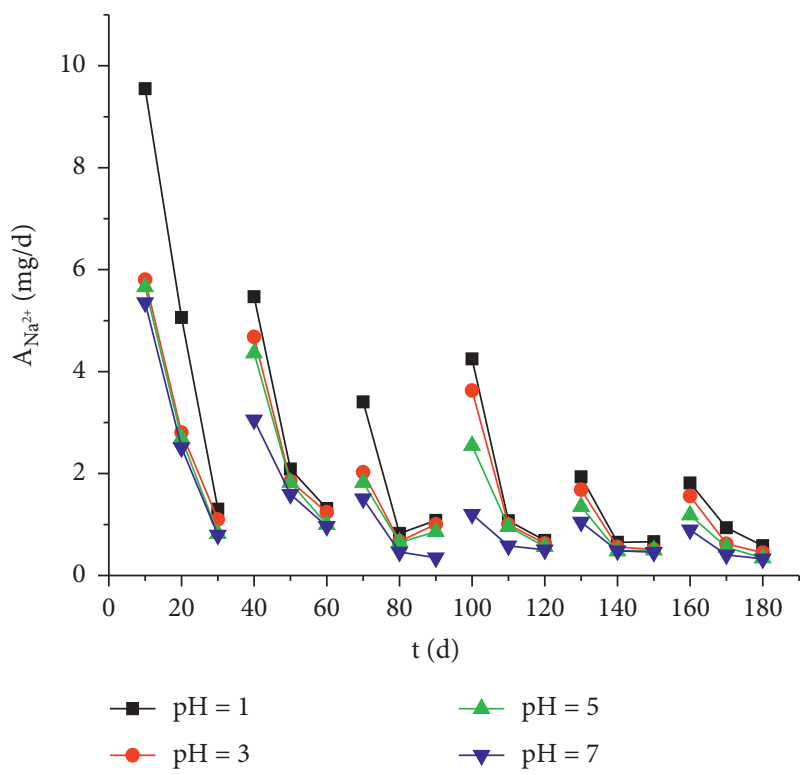

(c)

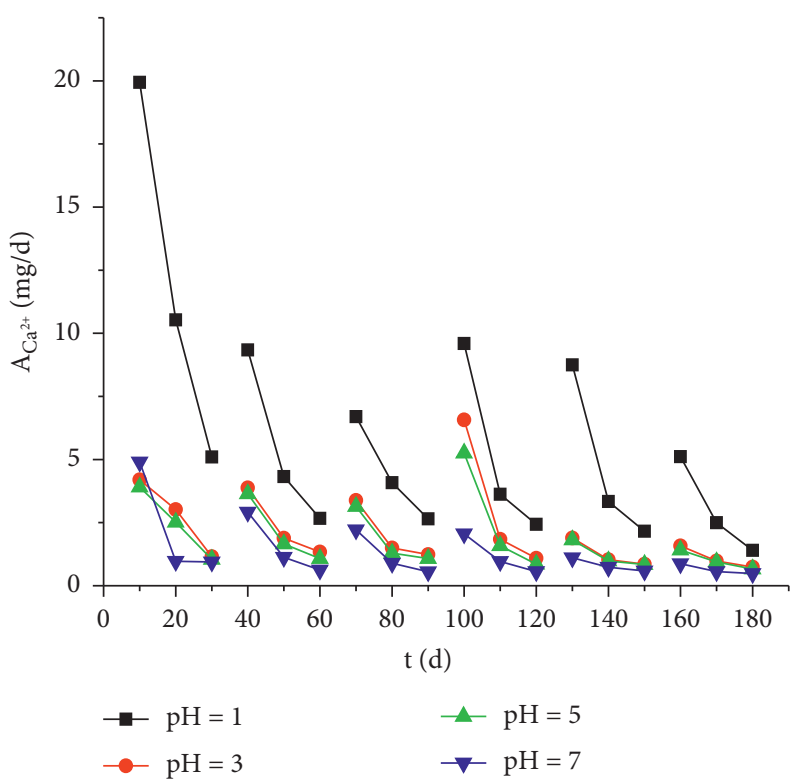

(b)

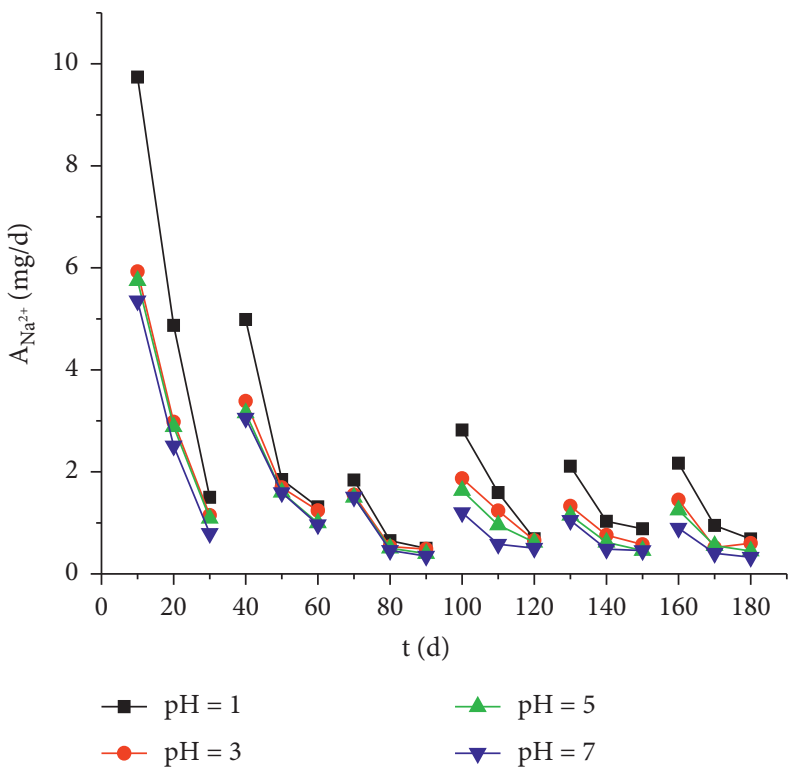

(d)

FIgURE 7: The change law of cation dissolution rate with time in different chemical solutions: (a) $\mathrm{Ca}^{2+}$ in sulfuric acid solution, (b) $\mathrm{Ca}^{2+}$ in hydrochloric acid solution, (c) $\mathrm{Na}^{+}$in sulfuric acid solution, and (d) $\mathrm{Na}^{+}$in hydrochloric acid solution.

the test, the destruction of rock samples was often accompanied by a crisp sound, and the stress drops rapidly after the failure of samples. Therefore, the postpeak stage has not been obtained.

(2) For different kinds of soaking solutions with different $\mathrm{pH}$ values, the characteristic of sandstone changes from brittleness to ductility with the increase of soaking time. The micropores in acidcorroded rock increase, and the rock becomes soft. The deformations of the compaction stage, the elastic stage, and the plastic stage all increase to varying extents, and the compaction stage and the elastic stage increase significantly. In the same soaking solution, the smaller the $\mathrm{pH}$ value is, the greater the effect on deformation is. After soaking for 180 days, the peak strains of rock samples in $\mathrm{H}_{2} \mathrm{SO}_{4}$ solution with $\mathrm{pH}=1,3$, and 5 are $0.0198,0.0132$, and 0.0118 , respectively, which are $4.92,3.27$, and 2.92 times of the initial peak strains. Under the same conditions, the corrosion degree of $\mathrm{HCl}$ solution is slightly greater than that of $\mathrm{H}_{2} \mathrm{SO}_{4}$ solution at all stages.

(3) The deterioration laws of strength parameters of rock samples soaking in different chemical solutions are basically the same. Under the same conditions, the $\mathrm{pH}$ value has a great influence on rock strength. After soaking for 180 days, the peak strength of sandstone 
TABLE 3: Uniaxial compressive test results of sandstone samples subjected to acid corrosion.

\begin{tabular}{|c|c|c|c|c|c|c|c|}
\hline $\begin{array}{l}\text { Corrosion } \\
\text { time }\end{array}$ & $\begin{array}{l}\text { Soak } \\
\text { solution }\end{array}$ & $\begin{array}{c}\text { Peak stress } \\
\sigma_{c}(\mathrm{MPa})\end{array}$ & $\begin{array}{c}\left(\sigma_{n}-\sigma_{c}\right) / \sigma_{n} \times 100 \% \\
(\%)\end{array}$ & $\begin{array}{c}\text { Peak } \\
\text { strain } \varepsilon_{c} \\
\left(10^{-3}\right)\end{array}$ & $\begin{array}{c}\left(\varepsilon_{c}-\varepsilon_{n}\right) / \varepsilon_{n} \times 100 \% \\
(\%)\end{array}$ & $\begin{array}{l}\text { Elastic } \\
\text { modulus } E \\
(\mathrm{GPa})\end{array}$ & $\begin{array}{c}\left(E_{n}-E\right) / E_{n} \times 100 \% \\
(\%)\end{array}$ \\
\hline 30 & & 58.14 & 34.12 & 5.37 & 33.25 & 14.79 & 38.76 \\
\hline 60 & $\mathrm{pH}=1$ & 52.37 & 40.66 & 9.33 & 131.51 & 7.36 & 69.52 \\
\hline 90 & $\mathrm{H}_{2} \mathrm{SO}_{4}$ & 49.06 & 44.41 & 12.01 & 198.01 & 5.71 & 76.36 \\
\hline 180 & & 45.71 & 48.20 & 19.82 & 391.81 & 3.50 & 85.51 \\
\hline 30 & & 64.04 & 27.43 & 5.11 & 26.80 & 15.63 & 35.28 \\
\hline 60 & $\mathrm{pH}=3$ & 59.86 & 32.17 & 8.39 & 108.19 & 9.11 & 62.28 \\
\hline 90 & $\mathrm{H}_{2} \mathrm{SO}_{4}$ & 57.67 & 34.65 & 10.64 & 164.02 & 7.03 & 70.89 \\
\hline 180 & & 54.39 & 38.37 & 13.17 & 226.80 & 6.01 & 75.11 \\
\hline 30 & & 69.7 & 21.02 & 4.95 & 22.83 & 19.13 & 20.79 \\
\hline 60 & $\mathrm{pH}=5$ & 65.04 & 26.30 & 7.61 & 88.83 & 11.51 & 52.34 \\
\hline 90 & $\mathrm{H}_{2} \mathrm{SO}_{4}$ & 62.02 & 29.72 & 9.48 & 135.24 & 8.13 & 66.34 \\
\hline 180 & & 60.20 & 31.78 & 11.78 & 192.31 & 7.24 & 70.02 \\
\hline 30 & & 56.78 & 35.66 & 5.23 & 29.78 & 14.53 & 39.83 \\
\hline 60 & $\mathrm{pH}=1$ & 51.74 & 41.37 & 9.68 & 140.20 & 6.96 & 71.18 \\
\hline 90 & $\mathrm{Hcl}$ & 46.91 & 46.84 & 12.65 & 213.90 & 5.08 & 78.96 \\
\hline 180 & & 41.73 & 52.71 & 20.78 & 415.63 & 2.38 & 90.14 \\
\hline 30 & & 65.55 & 25.72 & 5.03 & 24.81 & 15.88 & 34.24 \\
\hline 60 & $\mathrm{pH}=3$ & 58.17 & 34.08 & 8.96 & 122.33 & 8.54 & 64.64 \\
\hline 90 & $\mathrm{Hcl}$ & 54.25 & 38.53 & 10.17 & 152.36 & 7.35 & 69.57 \\
\hline 180 & & 49.53 & 43.88 & 13.65 & 238.71 & 5.06 & 79.05 \\
\hline 30 & & 68.89 & 21.94 & 4.93 & 22.33 & 18.02 & 25.38 \\
\hline 60 & $\mathrm{pH}=5$ & 64.24 & 27.21 & 7.72 & 91.56 & 11.42 & 52.71 \\
\hline 90 & $\mathrm{HCl}$ & 62.13 & 29.60 & 9.71 & 140.94 & 8.74 & 63.81 \\
\hline 180 & & 59.85 & 32.18 & 12.32 & 205.71 & 6.73 & 72.13 \\
\hline 30 & & 75.26 & 14.72 & 4.68 & 16.13 & 20.45 & 15.32 \\
\hline 60 & $\mathrm{pH}=7$ & 71.18 & 19.34 & 5.85 & 45.16 & 16.18 & 33.00 \\
\hline 90 & $\mathrm{H}_{2} \mathrm{O}$ & 67.73 & 23.25 & 6.88 & 70.72 & 12.82 & 46.92 \\
\hline 180 & & 63.52 & 28.02 & 9.05 & 124.57 & 8.418 & 65.14 \\
\hline Nature & & 88.25 & & 4.03 & & 24.15 & \\
\hline
\end{tabular}

Note that in this table, $\sigma_{n}, \varepsilon_{n}$, and $E_{n}$ are, respectively, peak strength, peak point axial strain, and elastic modulus of sandstone samples in a natural state.

samples in $\mathrm{H}_{2} \mathrm{SO}_{4}$ solution with $\mathrm{pH}=1,3$, and 5 decreases by $48.2 \%, 38.4 \%$, and $31.78 \%$, respectively. After soaking for 30 days, the peak strength of samples in hydrochloric acid and sulfuric acid solutions with $\mathrm{pH}=1$ decreases by $35.7 \%$ and $34.1 \%$, respectively, indicating that the strength mainly decreases in the early stage of the reaction. Under the same conditions, the peak strength of rock samples corroded by the hydrochloric acid solution is lower than that of samples corroded by the sulfuric acid solution, which indicates that the hydrochloric acid solution has a greater effect of deterioration on sandstone and sulfate radical has a slight inhibition effect on corrosion. The elastic modulus of acid-corroded sandstone decreases gradually with the extension of soaking time, and its variation range is more uniform than that of peak strength. Under the same conditions, the smaller the $\mathrm{pH}$ value is, the greater the change of elastic modulus of rock samples is. And the variation of elastic modulus of rock samples in $\mathrm{HCl}$ solution is slightly larger than that in $\mathrm{H}_{2} \mathrm{SO}_{4}$ solution. Because of the strong brittleness of sandstone samples, the destruction of sandstone samples is often accompanied by a crisp sound and the stress dropped rapidly after the failure of the samples, so the postpeak stage has not been obtained.

The relationships between the peak stress and elastic modulus of acid-corroded sandstone samples and the soaking time can be fitted by the following formula:

$$
y=a e^{b t}+c
$$

where $y$ is the peak strength (MPa) or elastic modulus (GPa), $t$ is soaking time $(d)$, and $a, b$, and $c$ are the fitting parameters, as shown in Table 4. The relationships between the peak strength and elastic modulus and soaking time are shown in Figures 9(a) and 9(b).

The relationship between the peak stain and soaking time can be fitted by the following formula:

$$
\varepsilon=\frac{a+(a-b)}{\left(1+\left(e^{t-c} / d\right)\right)},
$$

where $\varepsilon$ is the peak stain ( $\mathrm{mm})$ and $a, b$, and $c$ are the fitting parameters, as shown in Table 5. The relationships between the peak stain and soaking time are shown in Figure 9(c). 


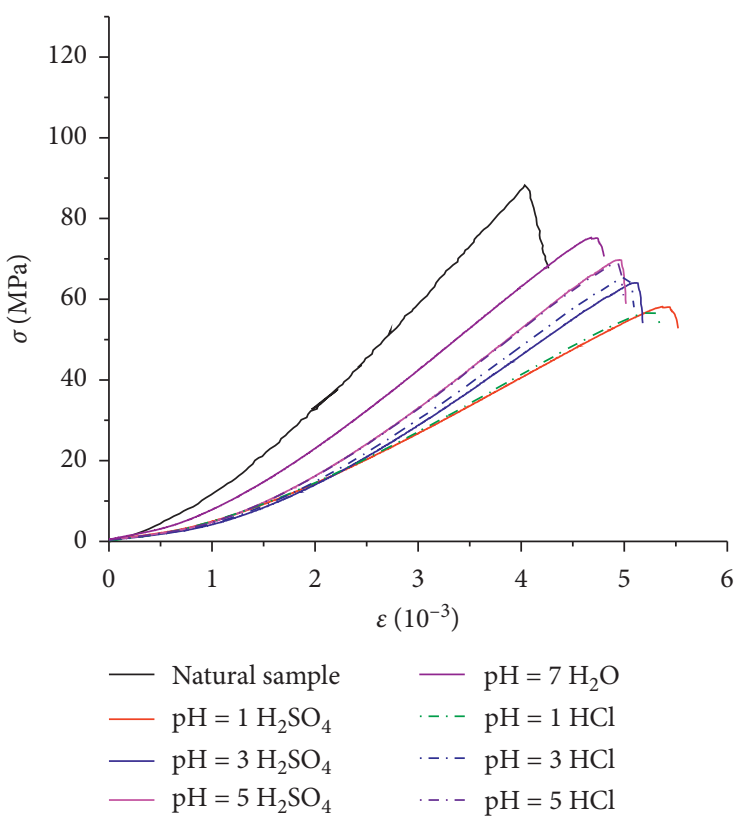

(a)

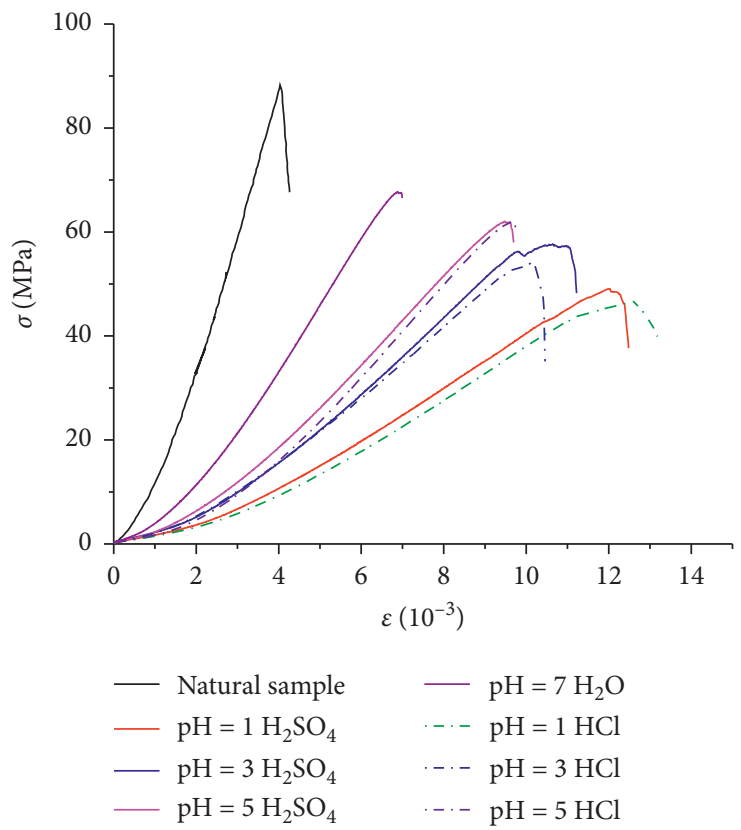

(c)

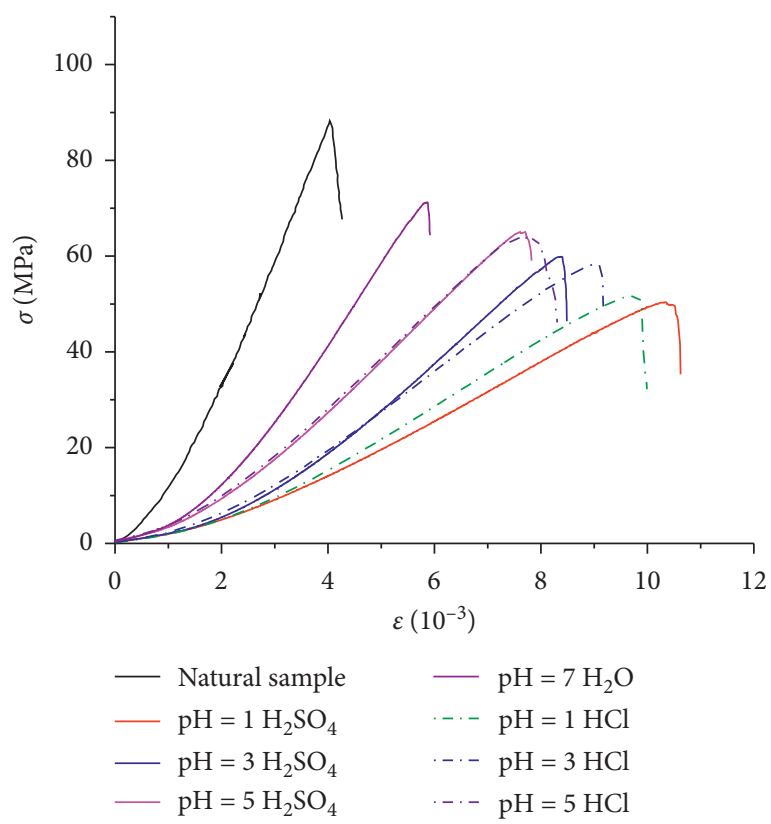

(b)

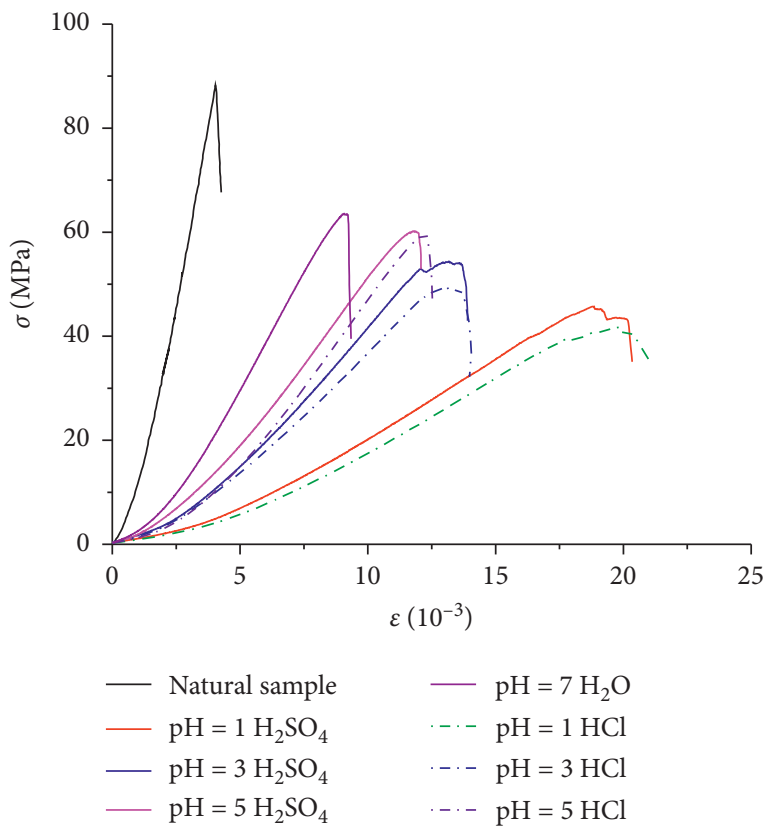

(d)

FIGURE 8: Uniaxial compressive stress-strain curves for sandstone samples attacked by acid solutions for different days: (a) soaking for 30 days, (b) soaking for 60 days, (c) soaking for 90 days, and (d) soaking for 180 days.

TABle 4: Fitting parameters of relationship between the peak stress and the elastic modulus and soaking time.

\begin{tabular}{lccccccccccc}
\hline Mechanical parameters & Soaking solution & $a$ & $b$ & $c$ & $R^{2}$ & Soaking solution & $a$ & $b$ & $c$ & $R^{2}$ \\
\hline & $\mathrm{pH}=1 \mathrm{H}_{2} \mathrm{SO}_{4}$ & 40.916 & -0.040 & 47.154 & 0.994 & $\mathrm{pH}=1 \mathrm{HCl}$ & 44.057 & -0.035 & 43.783 & 0.986 \\
& $\mathrm{pH}=3 \mathrm{H}_{2} \mathrm{SO}_{4}$ & 32.189 & -0.042 & 55.909 & 0.991 & $\mathrm{pH}=3 \mathrm{HCl}$ & 37.846 & -0.028 & 50.125 & 0.996 \\
Peak stress (MPa) & $\mathrm{pH}=5 \mathrm{H}_{2} \mathrm{SO}_{4}$ & 27.477 & -0.035 & 60.648 & 0.997 & $\mathrm{pH}=5 \mathrm{HCl}$ & 27.541 & -0.038 & 60.607 & 0.996 \\
& $\mathrm{pH}=7 \mathrm{H}_{2} \mathrm{O}$ & 24.431 & -0.021 & 63.477 & 0.992 & - & - & - & - & \\
& $\mathrm{pH}=1 \mathrm{H}_{2} \mathrm{SO}_{4}$ & 21.534 & -0.023 & 2.857 & 0.992 & $\mathrm{pH}=1 \mathrm{HCl}$ & 22.677 & -0.022 & 1.717 & 0.992 \\
\hline \multirow{5}{*}{ Elastic modulus (GPa) } & $\mathrm{pH}=3 \mathrm{H}_{2} \mathrm{SO}_{4}$ & 19.151 & -0.024 & 5.256 & 0.991 & $\mathrm{pH}=3 \mathrm{HCl}$ & 19.989 & -0.022 & 4.427 & 0.988 \\
& $\mathrm{pH}=5 \mathrm{H}_{2} \mathrm{SO}_{4}$ & 19.307 & -0.017 & 5.552 & 0.960 & $\mathrm{pH}=5 \mathrm{HCl}$ & 19.082 & -0.018 & 5.477 & 0.986 \\
& $\mathrm{pH}=7 \mathrm{H}_{2} \mathrm{O}$ & 20.604 & -0.009 & 3.858 & 0.994 & - & - & - & - & - \\
\hline
\end{tabular}




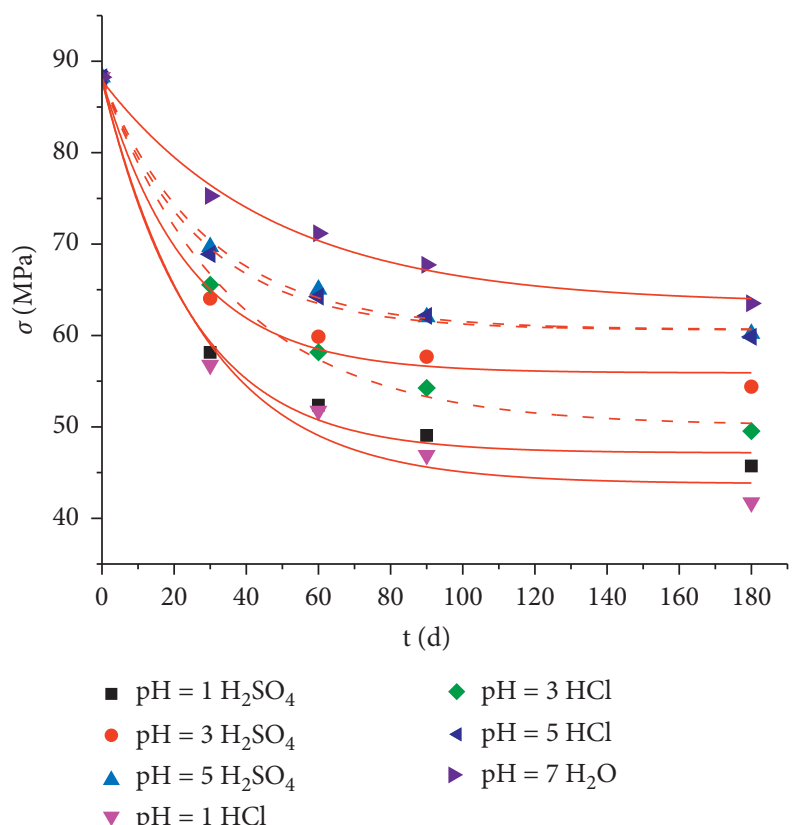

(a)

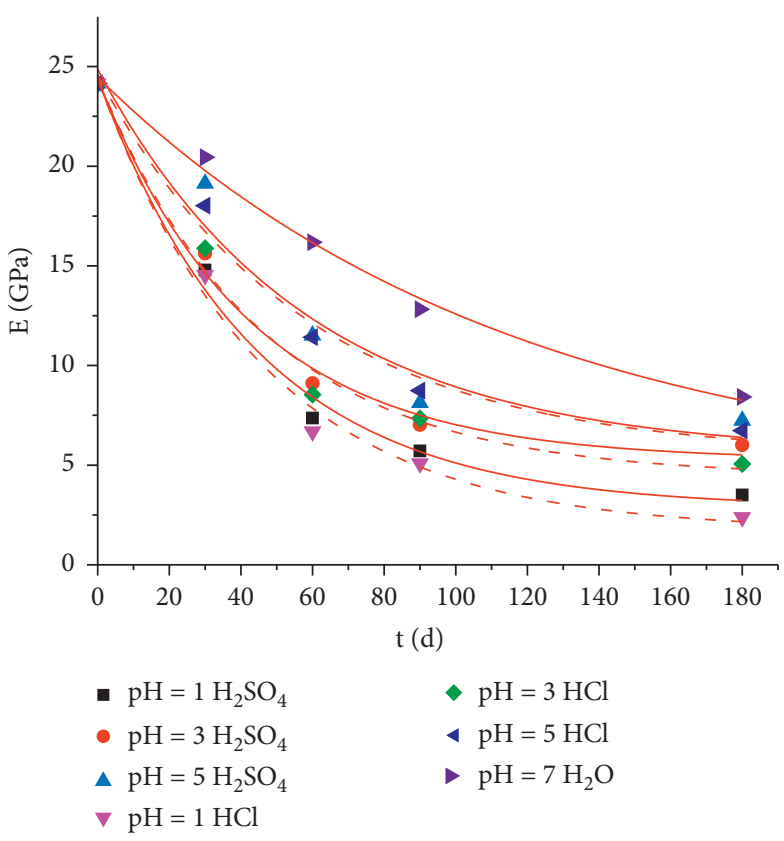

(b)

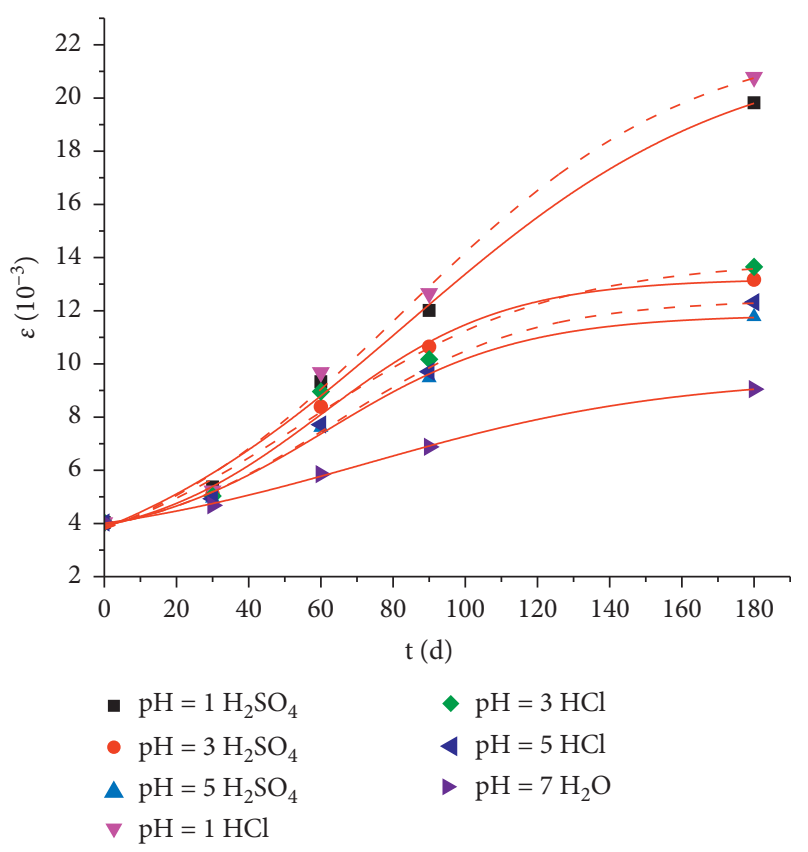

(c)

Figure 9: Relationship between (a) the peak stress, (b) the elastic modulus, and (c) the peak stain of sandstone samples and soaking time.

\section{Quantitative Damage Analysis of Acid- Corroded Sandstone Based on CT}

The main cause of the nonlinearity of mechanical properties of sandstone is the heterogeneity of the microstructure of rocks. Therefore, based on the damage variables defined by the microstructure of rocks, the macroscopic mechanical effect can be better analyzed. The chemical reaction between the rocks and the acid solution causes the internal micropores to expand and penetrate. The cohesive force between the particles decreases, resulting in a decrease in the effective bearing area, a decrease in mechanical parameters, and a deeper deterioration. Computer tomographic identification technology (CT) can describe the physical parameters of rocks quantitatively by CT number. Through the observation of CT images and the quantitative analysis of CT numbers, the change in the formation, permeability depth, and the path of microvoids of rock samples can be obtained, and the mechanical characteristics of corrosion damage of sandstone can be more intuitively linked with the change of internal microstructures.

Figure 10 shows CT scanning images of the middle layer of sandstone samples subjected to two different solutions. 
TABLE 5: Fitting parameters of relationship between peak strain and soaking time.

\begin{tabular}{|c|c|c|c|c|c|c|c|c|c|c|c|c|}
\hline Mecha & Soaking solution & $a$ & $b$ & $c$ & $d$ & $R^{2}$ & Soaking solution & $a$ & $b$ & $c$ & $d$ & $R^{2}$ \\
\hline \multirow{4}{*}{ Peak strain $\left(10^{-3}\right)$} & $\mathrm{pH}=1 \mathrm{H}_{2} \mathrm{SO}_{4}$ & 4 & 2.038 & 858 & 153 & 0.996 & $-1 \mathrm{HCl}$ & 1.377 & 22.463 & 82.427 & 40.169 & 0.995 \\
\hline & $\mathrm{pH}$ & 3.072 & 13.205 & 60.410 & 25.065 & 0.996 & & 1.823 & 13.899 & 56.229 & 34.521 & 0.980 \\
\hline & $\mathrm{SO}_{4}$ & 3.149 & 11.845 & 61.572 & 26.602 & 0.996 & $\mathrm{pH}=5 \mathrm{HCl}$ & 3.098 & 12.411 & 63.538 & 27.143 & 0.996 \\
\hline & $\mathrm{pH}=7 \mathrm{H}_{2} \mathrm{O}$ & 3.015 & 9.534 & 73.119 & 42.502 & 0.999 & - & - & - & - & - & 一 \\
\hline
\end{tabular}

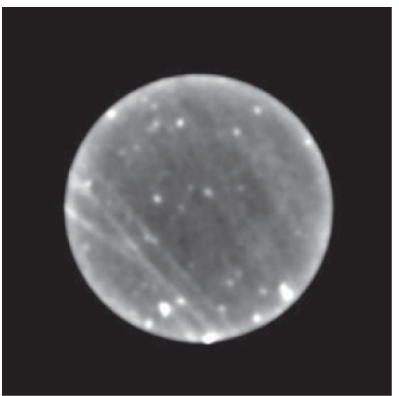

(a)

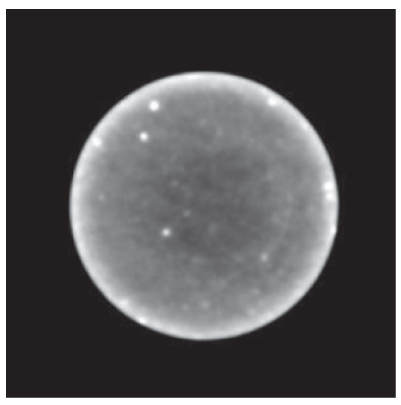

(e)

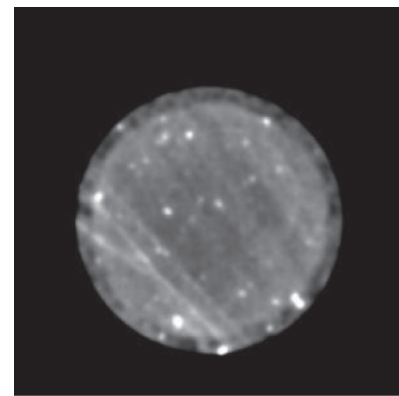

(b)

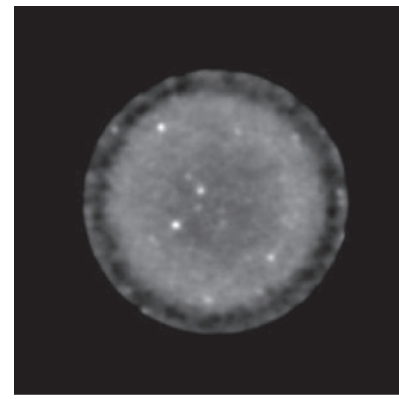

(f)

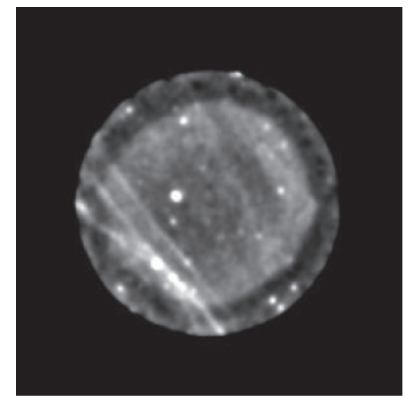

(c)

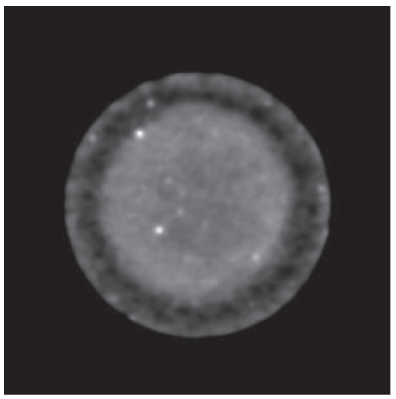

(g)

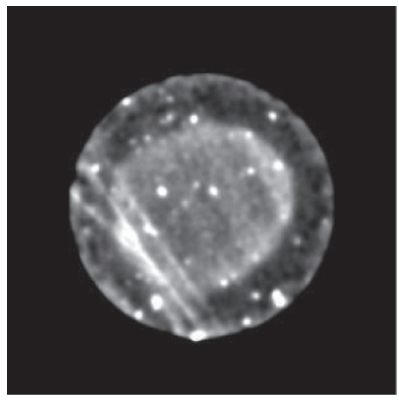

(d)

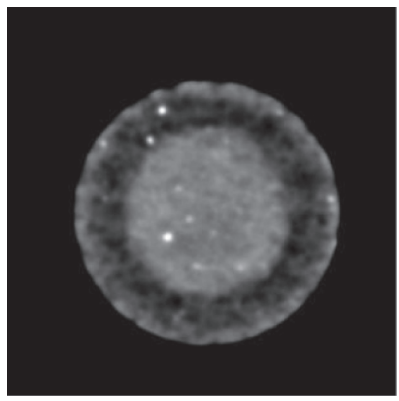

(h)

Figure 10: CT images of the middle layer of sandstone specimens subjected to different solutions for different stages: $(\mathrm{a}) \mathrm{pH}^{2} 3 \mathrm{H}_{2} \mathrm{SO}_{4}(0$ days), (b) $\mathrm{pH}=3 \mathrm{H}_{2} \mathrm{SO}_{4}$ (30 days), (c) $\mathrm{pH}=3 \mathrm{H}_{2} \mathrm{SO}_{4}$ (90 days), (d) $\mathrm{pH}=3 \mathrm{H}_{2} \mathrm{SO}_{4}$ (180 days), (e) $\mathrm{pH}=1 \mathrm{HCl}(0 \mathrm{days}),(\mathrm{f}) \mathrm{pH}=1 \mathrm{HCl}(30$ days), (g) $\mathrm{pH}=1 \mathrm{HCl}$ (90 days), and (h) $\mathrm{pH}=1 \mathrm{HCl}$ (180 days).

The corrosion damage degree of samples subjected to the solution with the same $\mathrm{pH}$ value is obviously different in different stages, and the smaller the $\mathrm{pH}$ value of the solution is, the more seriously the rock samples are corroded. The author had carried out a detailed analysis of the damage of acid-corroded sandstone based on CT histogram technology in $[12,13]$. According to the literature in [13], the formulas for calculating damage variables of acid-corroded sandstone are as follows:

$$
D=\frac{1}{2}\left(D_{1}+D_{2}\right)=1-\frac{E\left(\rho_{1}\right)+E\left(\rho_{2}\right)}{2 \rho_{0}},
$$

where $D$ is the damage variable of acid-corroded sandstone, $D_{1}$ and $D_{2}$ are the damage variable of corroded and noncorroded rocks, and $\rho_{1}$ and $\rho_{2}$ are the density of corroded and noncorroded rocks, respectively $\left(\mathrm{g} / \mathrm{cm}^{3}\right)$.

According to the literature in [28], the relationship between the CT number and the rock density is as follows:

$$
\rho=\frac{1000+H}{1000+H_{r}} \rho_{r},
$$

where $H$ is the CT number of the damaged sandstone, $H_{r}$ is the CT number of sandstone matrix material, and $\rho_{\mathrm{r}}$ is the density of sandstone matrix material.

Equations (5) and (6) can solve the damage variables of the scanned cross section of the acid-corroded sandstone based on the CT number. The calculated damage variables at different corrosion stages of the middle scanning layer of sandstone samples attacked by the hydrochloric acid and sulfuric acid solution with different $\mathrm{pH}$ values are shown in Table 6 . It can be seen from Table 6 that the chemical damage of rock samples in different acidic solutions in different soaking stages is different. With the increase of acidity of soaking solution and soaking time, the damage variables of rock sample increase, and the stronger the acidity, the greater the increase of damage variable. 
TABLE 6: Damage variables of the intermediate scanning layer of rock samples at different time intervals in different solutions.

\begin{tabular}{lcc}
\hline Soaking time & Corrosion time (days) & Damage variables (D) \\
\hline & 30 & 0.1935 \\
$\mathrm{pH}=1 \mathrm{H}_{2} \mathrm{SO}_{4}$ & 60 & 0.2825 \\
& 90 & 0.3416 \\
& 180 & 0.5038 \\
\hline & 30 & 0.1412 \\
$\mathrm{pH}=3 \mathrm{H}_{2} \mathrm{SO}_{4}$ & 60 & 0.2135 \\
& 90 & 0.2614 \\
& 180 & 0.3507 \\
$\mathrm{pH}=5 \mathrm{H}_{2} \mathrm{SO}_{4}$ & 30 & 0.1308 \\
& 60 & 0.1754 \\
& 90 & 0.2097 \\
$\mathrm{pH}=1 \mathrm{HCl}$ & 180 & 0.2813 \\
\hline $\mathrm{pH}=3 \mathrm{HCl}$ & 30 & 0.2123 \\
& 60 & 0.3014 \\
& 90 & 0.3602 \\
$\mathrm{pH}=5 \mathrm{HCl}$ & 180 & 0.5184 \\
\hline & 30 & 0.1685 \\
& 60 & 0.2310 \\
& 90 & 0.2732 \\
& 180 & 0.3713 \\
\hline & 30 & 0.1385 \\
& 60 & 0.1886 \\
& 90 & 0.2301 \\
& 180 & 0.2988 \\
\hline & &
\end{tabular}

The relationship between the damage variable of acidcorroded sandstone samples and the soaking time can be fitted by the following formula:

$$
D(t)=a t^{b},
$$

where $t$ is the soaking time $(d) ; a$ and $b$ are the fitting parameters, as shown in Table 5. The relationship between the damage variables and soaking time is shown in Figure 11.

The relationship between the damage variables of the acid-corroded sandstone and peak strength, peak strain, and elastic modulus can be fitted by the following formula:

$$
y=a e^{b D}+c
$$

where $D$ is the damage variable, $y$ is the peak strength (MPa), peak strain, and elastic modulus $(\mathrm{GPa})$, and $a, b$, and $c$ are the fitting parameters, as shown in Tables 7 and 8. The relationships between the damage variables and peak strength, peak strain, and elastic modulus are shown in Figures 12(a)-12(c).

It can be seen from Figure 11 that the damage variable of the sandstone samples increases with the increase of soaking time in the acidic environment. When the soaking solution is the same, the damage variable of the rock samples increases with the decrease of the $\mathrm{pH}$ value of the solution. The damage variable of the rock samples in the hydrochloric acid

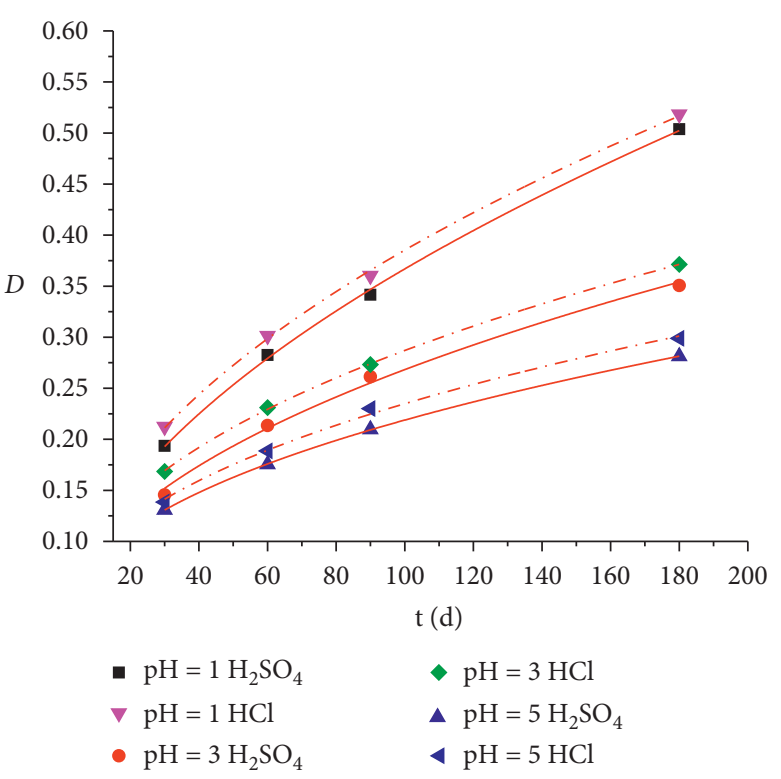

FIGURE 11: Relationship between the damage variables of the sandstone samples and soaking time.

TABLE 7: Regression parameters of the relationship between the damage variables and soaking time.

\begin{tabular}{lccc}
\hline Soaking solution & $a$ & $b$ & $R^{2}$ \\
\hline $\mathrm{pH}=1 \mathrm{H}_{2} \mathrm{SO}_{4}$ & 0.031 & 0.534 & 0.999 \\
$\mathrm{pH}=3 \mathrm{H}_{2} \mathrm{SO}_{4}$ & 0.030 & 0.472 & 0.996 \\
$\mathrm{pH}=5 \mathrm{H}_{2} \mathrm{SO}_{4}$ & 0.031 & 0.428 & 0.996 \\
$\mathrm{pH}=1 \mathrm{HCl}$ & 0.039 & 0.499 & 0.999 \\
$\mathrm{pH}=3 \mathrm{HCl}$ & 0.038 & 0.438 & 0.999 \\
$\mathrm{pH}=5 \mathrm{HCl}$ & 0.034 & 0.422 & 0.997 \\
\hline
\end{tabular}

solution is larger than that in the sulfuric acid solution with the same $\mathrm{pH}$ value, and the difference between the two decreases with the extension of soaking time. It can be seen from Figures 12(a) and 12(c) that the peak strength and elastic modulus of the acid-corroded sandstone decrease with the increase of damage variable, and the decreasing rate gradually decreases with the increase of damage variable. It can be seen from Figure 12(b) that the peak strain of acidcorroded rock samples increases as damage variable increases. The above analysis shows that as the chemical damage of sandstone samples becomes more and more serious, the mechanical properties of the sandstone samples gradually deteriorate. However, the plastic deformation of the rock samples gradually increases. The damage variable of the acid-corroded sandstone samples has a power function relationship with the corrosion time and an exponential function relationship with the peak strength, peak strain, and elastic modulus. 
TABLE 8: Fitting parameters of relationship between damage variable and peak strength.

\begin{tabular}{lcccccccccc}
\hline Mechanical parameters & Soaking solution & $a$ & $b$ & $c$ & $R^{2}$ & Soaking solution & $a$ & $b$ & $c$ & $R^{2}$ \\
\hline \multirow{3}{*}{ Peak stress (MPa) } & $\mathrm{pH}=1 \mathrm{H}_{2} \mathrm{SO}_{4}$ & 97.182 & -10.989 & 3.201 & 0.998 & $\mathrm{pH}=1 \mathrm{HCl}$ & 99.241 & -9.709 & 1.801 & 0.998 \\
& $\mathrm{pH}=3 \mathrm{H}_{2} \mathrm{SO}_{4}$ & 80.707 & -14.706 & 5.463 & 0.999 & $\mathrm{pH}=3 \mathrm{HCl}$ & 160.863 & -15.873 & 4.792 & 0.994 \\
& $\mathrm{pH}=5 \mathrm{H}_{2} \mathrm{SO}_{4}$ & 251.895 & -22.727 & 6.616 & 0.994 & $\mathrm{pH}=5 \mathrm{HCl}$ & 101.375 & -15.151 & 5.652 & 0.999 \\
\hline \multirow{3}{*}{ Peak strain $\left(10^{-3}\right)$} & $\mathrm{pH}=1 \mathrm{H}_{2} \mathrm{SO}_{4}$ & -136.857 & -0.359 & 133.024 & 0.999 & $\mathrm{pH}=1 \mathrm{HCl}$ & -96.811 & -0.615 & 90.179 & 0.999 \\
& $\mathrm{pH}=3 \mathrm{H}_{2} \mathrm{SO}_{4}$ & -25.711 & -3.484 & 20.779 & 0.997 & $\mathrm{pH}=3 \mathrm{HCl}$ & -30.601 & -4.808 & 18.731 & 0.994 \\
& $\mathrm{pH}=5 \mathrm{H}_{2} \mathrm{SO}_{4}$ & -26.029 & -6.711 & 15.758 & 0.998 & $\mathrm{pH}=5 \mathrm{HCl}$ & -27.452 & -3.802 & 21.141 & 0.999 \\
\hline \multirow{3}{*}{ Elastic modulus (GPa) } & $\mathrm{pH}=1 \mathrm{H}_{2} \mathrm{SO}_{4}$ & 97.182 & -11.001 & 3.201 & 0.998 & $\mathrm{pH}=1 \mathrm{HCl}$ & 99.241 & -9.709 & 1.801 & 0.998 \\
& $\mathrm{pH}=3 \mathrm{H}_{2} \mathrm{SO}_{4}$ & 80.707 & -14.706 & 5.463 & 0.999 & $\mathrm{pH}=3 \mathrm{HCl}$ & 160.863 & -15.873 & 4.792 & 0.994 \\
& $\mathrm{pH}=5 \mathrm{H}_{2} \mathrm{SO}_{4}$ & 251.895 & -22.727 & 6.616 & 0.994 & $\mathrm{pH}=5 \mathrm{HCl}$ & 101.375 & -15.151 & 5.652 & 0.999 \\
\hline
\end{tabular}

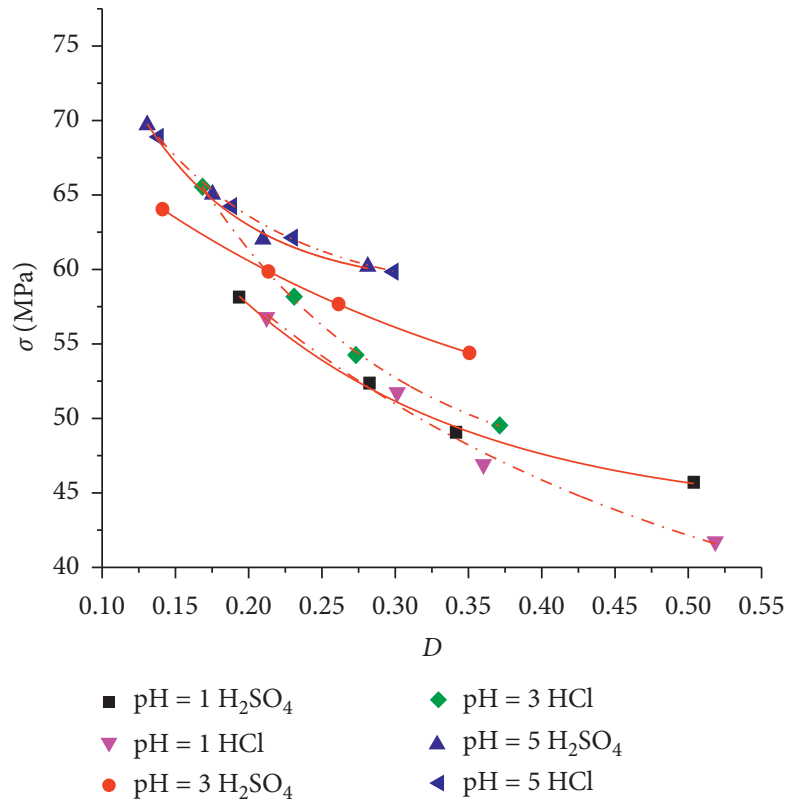

(a)

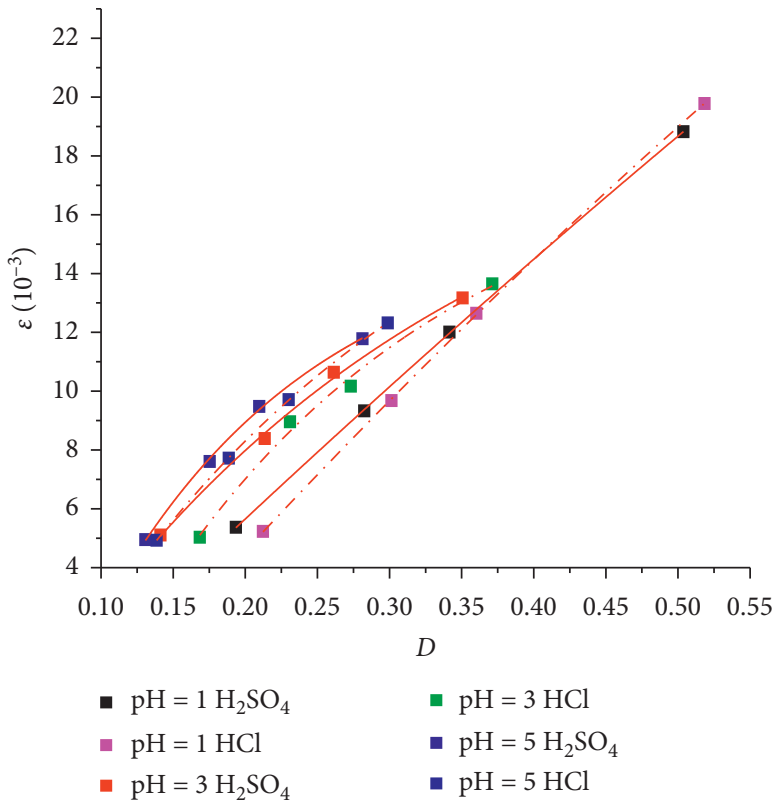

(b)

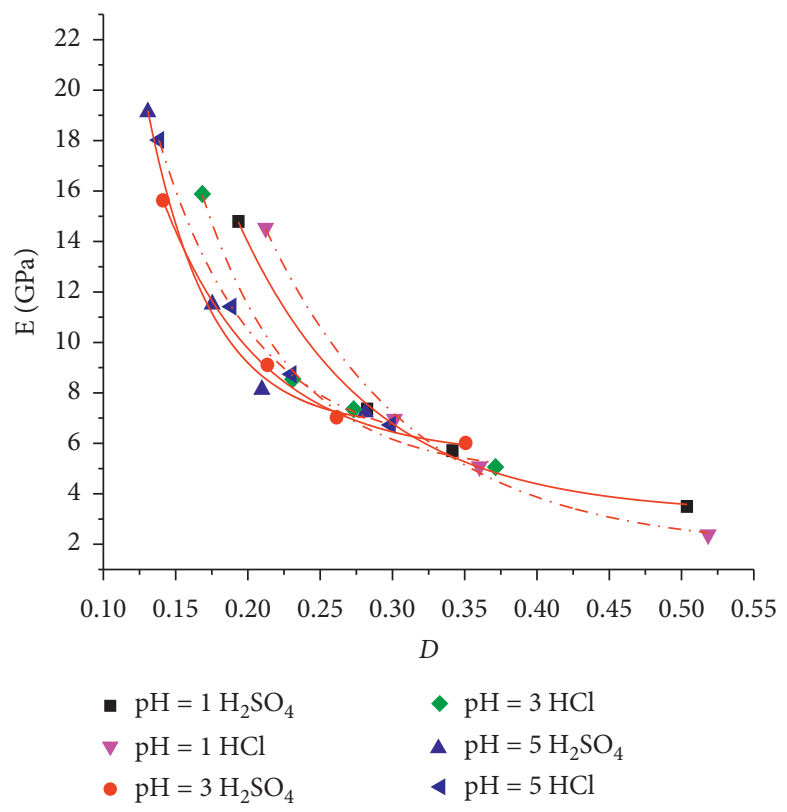

(c)

FIGURE 12: Relationship between the damage variables of the sandstone samples and (a) peak stress, (b) peak strain, and (c) elastic modulus. 


\section{Conclusions}

Based on the results of this study, the following conclusions can be drawn:

(1) In the acidic environment, the $\mathrm{pH}$ value of the soaking solution and the mass change of the sandstone sample have visible phased characteristics. The smaller the $\mathrm{pH}$ value of the soaking solution is, the more violent the reaction between the soaking solution and the rock is, and the higher the change rate and amplitude of the mass loss rate are. The $\mathrm{pH}$ value of the solution increased rapidly at the initial of each soaking stage (30 days) and stabilized gradually with the prolongation of the corrosion time. The mass change rate shows an increasing trend in the whole corrosion stage, and its growth rate gradually decreased and tended to be stable. Under the same soaking conditions, the corrosion of hydrochloric acid solution to sandstone was more durable than that of sulfuric acid solution.

(2) With the extension of soaking time and the increase of acidity, the compaction stage of the rock samples became longer, and the elastic stage became shorter. The damage of the sandstone samples showed ductile characteristics gradually. The smaller the $\mathrm{pH}$ value of the soaking solution was, the greater the deterioration degree of mechanical parameters of rock samples was. Under the same conditions, the deterioration degree of the hydrochloric acid solution was similar to that of sulfuric acid solution at the initial stage of soaking. With the extension of corrosion time, the deterioration degree of the hydrochloric acid solution was greater than that of sulfuric acid solution.

(3) With the same soaking solution, the smaller the $\mathrm{pH}$ value was, the greater the dissolution rate of $\mathrm{Ca}^{2+}$ and $\mathrm{Na}^{+}$was. With the extension of corrosion penetration path, the dissolution rate fluctuated with soaking time, indicating that the process of acid corrosion of rocks had a phased characteristic. Under the same $\mathrm{pH}$ value, the dissolution rate of $\mathrm{Ca}^{2+}$ in the sulfuric acid solution was less than that in the hydrochloric acid solution, and the dissolution rate of $\mathrm{Na}^{+}$is the same approximately. The cation dissolution rate under the action of the weak acid with higher $\mathrm{pH}$ value was not significantly different from that under the action of distilled water with $\mathrm{pH}=7$.

(4) The damage variable of acid-corroded sandstone based on CT number was calculated, and the macroscopic mechanical effect of corroded rocks was expressed by mesoscopic damage variables quantificationally. The regression analysis shows that the damage variable has a power function relationship with the corrosion time and an exponential function relationship with the peak strength, peak point strain, and elastic modulus of acid-corroded sandstone.

\section{Data Availability}

The data included in this study are available from the corresponding author upon request.

\section{Conflicts of Interest}

The authors declare that they have no conflicts of interest.

\section{Acknowledgments}

The authors would like to thank the National Natural Science Foundation of China (41172237), China Railway 20th Bureau Group Co. Ltd. (YF2000SD01A) and China Postdoctoral Science Foundation (2020M673525) for supporting this research project.

\section{References}

[1] T. L. Han, J. P. Shi, Y. S. Chen, Z. H. Li, and C. L. Li, "Laboratory investigation on the mechanical properties of sandstone immersed in different chemical corrosion under freeze-thaw cycles," Chinese Journal of Solid Mechanics, vol. 38, no. 6, pp. 503-520, 2017.

[2] T. L. Han, J. P. Shi, Y. S. Chen, and M. Yang, "Laboratory investigation on the mode-I fracture toughness and its correlation with the strength characteristic of sandstone immersed in different chemical solutions," Chinese Journal of Solid Mechanics, vol. 38, no. 5, pp. 76-89, 2017.

[3] H. Li, Z. Zhong, X. Liu, Y. Sheng, and D. Yang, "Microdamage evolution and macro-mechanical property degradation of limestone due to chemical effects," International Journal of Rock Mechanics and Mining Sciences, vol. 110, pp. 257-265, 2018.

[4] E. Mohtarami, A. Baghbanan, M. Akbariforouz, H. Hashemolhosseini, and E. Asadollahpour, "Chemically dependent mechanical properties of natural andesite rock fractures," Canadian Geotechnical Journal, vol. 55, no. 6, pp. 881-893, 2017.

[5] E. Mohtarami, A. Baghbanan, M. Akbariforouz, and H. Hashemolhosseini, "Investigating of chemical effects on rock fracturing using extended finite element method," Theoretical and Applied Fracture Mechanics, vol. 89, pp. 110-126, 2017.

[6] S. Portier and F. D. Vuataz, "Developing the ability to model acid-rock interactions and mineral dissolution during the RMA stimulation test performed at the Soultz-sous-Forêts EGS site, France," Comptes Rendus Geoscience, vol. 342, no. 78, pp. 668-675, 2010.

[7] J. Taron and D. Elsworth, "Thermal-hydrologic-mechanicalchemical processes in the evolution of engineered geothermal reservoirs," International Journal of Rock Mechanics and Mining Sciences, vol. 46, no. 5, pp. 855-864, 2009.

[8] S. L. Chen, X. T. Feng, and S. J. Li, "Effects of chemical erosion on uniaxial compressive strength and meso-fracturing behaviors of rock," Journal of Rock Mechanics and Engineering, vol. 22, no. 4, pp. 547-551, 2003.

[9] R. K. Huo, F. Han, S. G. Li, and G. J. Wang, "Experimental study on physicochemical and mechanical properties of acidcorroded sandstone," Journal of Xi'an University of Architecture \& Technology, vol. 51, no. 1, pp. 21-26, 2019.

[10] R. K. Huo, G. J. Wang, S. G. Li, Z. Z. Ren, and F. Han, "Mechanics properties and pore structure change of acids 
corroded sandstone," Journal of Yangtze River Scientific Research Institute, vol. 36, no. 12, pp. 96-101, 2019.

[11] R. K. Huo, S. G. Li, and Y. Ding, "Experimental study on physicochemical and mechanical properties of mortar subjected to acid corrosion," Advances in Materials Science and Engineering, vol. 2018, Article ID 3283907, 11 pages, 2018.

[12] R. K. Huo, S. G. Li, F. Han, and G. J. Wang, "CT analysis on mesoscopic structure of sandstone under acidic environment," Indian Journal of Geo-Marine Sciences, vol. 47, no. 5, pp. 962-971, 2018.

[13] S. G. Li, R. K. Huo, B. Wang et al., "Experimental study on physicomechanical properties of sandstone under acidic environment," Advances in Civil Engineering, vol. 2018, Article ID 5784831, 15 pages, 2018.

[14] S. Li, R. Huo, F. Yoshiaki, D. Ren, and Z. Song, "Effect of acidtemperature-pressure on the damage characteristics of sandstone," International Journal of Rock Mechanics and Mining Sciences, vol. 122, Article ID 104079, 2019.

[15] J. Xu, H. Wu, L. C. Cheng, J. Liu, and W. J. Zhou, "Experimental study of shearing failure properties of sandstone under acidic conditions," Chinese Journal of Rock Mechanics and Engineering, vol. 31, no. Supp. 2, pp. 3898-3903, 2012.

[16] P. Li, J. Liu, and G. H. Li, "Experimental study for shear strength characteristics of sandstone under water-rock interaction effects," Rock and Soil Mechanics, vol. 32, no. 2, pp. 380-386, 2011.

[17] Y. L. Chen, P. Wang, X. W. Zhang, and X. Du, "Experimental research on mechanical properties of granite in chemical dissolution under freeze-thaw cycles," Chinese Journal of Geotechnical Engineering, vol. 36, no. 12, pp. 2227-2235, 2014.

[18] W. X. Ding, T. Xu, H. Y. Wang, and J. P. Chen, "Experimental study of mechanical property of limestone under coupled chemical solution and freeze-thaw process," Chinese Journal of Rock Mechanics and Engineering, vol. 34, no. 5, pp. 979985, 2015.

[19] T. L. Han, J. P. Shi, and X. S. Cao, "Fracturing and damage to sandstone under coupling effects of chemical corrosion and freeze-thaw cycles," Rock Mechanics and Rock Engineering, vol. 49, no. 11, pp. 1-11, 2016.

[20] F. Gao, Q. Wang, H. Deng, J. Zhang, W. Tian, and B. Ke, "Coupled effects of chemical environments and freeze-thaw cycles on damage characteristics of red sandstone," Bulletin of Engineering Geology and the Environment, vol. 76, no. 4, pp. 1481-1490, 2017.

[21] W. Wang, X. H. Li, Q. Z. Zhu, C. Shi, and W. Y. Xu, "Experimental study of mechanical characteristics of sandy slate under chemical corrosion," Rock and Soil Mechanics, vol. 38, no. 9, pp. 2559-2573, 2017.

[22] W. Wang, T. G. Liu, and J. F. Shao, "Effects of acid solution on the mechanical behavior of sandstone," Journal of Materials in Civil Engineering, vol. 28, no. 1, 2016.

[23] T. L. Han, Y. S. Chen, J. P. Shi, Z. Yu, and M. M. He, "Experimental study of mechanical characteristics of sandstone top to hydrochemical erosion," Chinese Journal of Rock Mechanics and Engineering, vol. 32, no. Supp. 2, pp. 30653072, 2013.

[24] C. M. He and J. C. Guo, "Mechanism study of acid on mechanical properties of limestone," Journal of Rock Mechanics and Engineering, vol. 32, no. Supp. 2, pp. 3016-3021, 2013.

[25] W. X. Ding, J. P. Chen, T. Xu, H. J. Chen, and H. Y. Wang, "Mechanical and chemical characteristics of limestone during chemical erosion," Rock and Soil Mechanics, vol. 36, no. 7, pp. 1825-1830, 2015.
[26] S. Y. Xie, J. F. Shao, and W. Y. Xu, "Influences of chemical degradation on mechanical behaviour of a limestone," International Journal of Rock Mechanics and Mining Sciences, vol. 48, no. 5, pp. 741-747, 2011.

[27] T. Ma, C. Yang, P. Chen, X. Wang, and Y. Guo, "On the damage constitutive model for hydrated shale using CT scanning technology," Journal of Natural Gas Science and Engineering, vol. 28, pp. 204-214, 2016.

[28] T. Ma and P. Chen, "Study of meso-damage characteristics of shale hydration based on CT scanning technology," Petroleum Exploration and Development, vol. 41, no. 2, pp. 249-256, 2014.

[29] G. S. Yang, D. Y. Xie, and C. Q. Zhang, "The quantitative analysis of distribution regulation of CT values of rock damage," Chinese Journal of Rock Mechanics and Engineering, vol. 17, no. 3, pp. 279-285, 1998.

[30] Y. Fu, Z. J. Wang, X. R. Liu et al., "Meso damage evolution characteristics and macro degradation of sandstone under wetting-drying cycles," Chinese Journal of Geotechnical Engineering, vol. 12, no. 4, pp. 1653-1666, 2017.

[31] GB/T50266-2013, Standard for Tests Method of Engineering Rock Masses, China Planning Press, Beijing, China, 2013. 